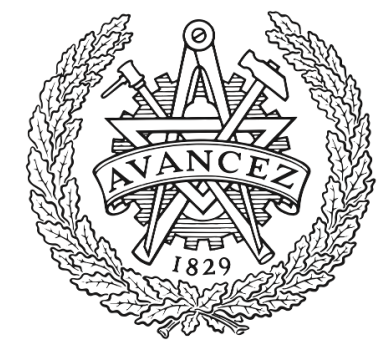

CHALMERS

UNIVERSITY OF TECHNOLOGY

\title{
Influence of in-bed catalysis by ash-coated olivine on tar formation in steam gasification of biomass
}

Downloaded from: https://research.chalmers.se, 2023-04-26 15:34 UTC

Citation for the original published paper (version of record):

Berdugo Vilches, T., Seemann, M., Thunman, H. (2018). Influence of in-bed catalysis by ash-coated olivine on tar formation in steam gasification of

biomass. Energy \& Fuels, 32(9): 9592-9604. http://dx.doi.org/10.1021/acs.energyfuels.8b02153

N.B. When citing this work, cite the original published paper. 
"This document is the Accepted Manuscript version of a Published Work that appeared in final form in Energy \& Fuel, copyright (c) American Chemical Society after peer review and technical editing by the publisher. To access the final edited and published work see https://pubs.acs.org/doi/10.1021/acs.energyfuels.8b02153” 


\title{
Influence of in-bed catalysis by ash-coated olivine on tar formation in steam gasification of biomass
}

\author{
Teresa Berdugo Vilches, Martin Seemann, Henrik Thunman \\ Department of Space, Earth and Environment (SEE), Chalmers University of Technology, 41296-Göteborg
}

\begin{abstract}
The use of catalytic bed materials represents a state-of-the-art solution for controlling the concentration of tars in fluidized bed biomass steam gasifiers. Ash-coated olivine is commonly applied as a bed material in gasifiers, owing to its relatively high catalytic activity towards tar species. However, the mechanisms and conversion pathways that are influenced by the ashcoated olivine used as an in-bed catalyst are not fully understood. The present work examines how ash-layered olivine prevents the formation of biomass-derived tar at an early stage of their formation. Tests involving olivine at different stages of activation and at different temperatures were carried out in the Chalmers 2-4-MW $\mathrm{MW}_{\text {th }} \mathrm{DFB}$ gasifier. A detailed characterization of the tar and light hydrocarbon fractions is presented and discussed in relation to the sources of the aromatic species. It is concluded that the ash-coated olivine prevents the formation of aromatic tar species by promoting steam reforming of early tar precursors. Gas-phase interactions of the early tar precursors and bed material contribute to the observed tar reduction. The results indicate that olivine interferes with the cyclization routes that involve $\mathrm{C}_{2} \mathrm{H}_{2}$ and $\mathrm{C}_{3}$ hydrocarbons.
\end{abstract}

Keywords: olivine, biomass, tar, reaction pathways, catalysis, cracking, reforming, gasification, in-bed catalysis, dual fluidized bed. 


\section{Introduction}

Biomass gasification in a fluidized bed offers an alternative and renewable way to produce heat, electricity, fuels, and chemicals. A major challenge in fluidized bed steam gasification is the uncontrolled formation of heavy tars, which can cause clogging of downstream equipment leading to costly unplanned operational stops. One solution is the application of catalytic bed materials in the gasifier to reduce the tar levels. In a dual fluidized bed (DFB) gasifier, the state-of-the-art bed material is olivine, which is a naturally occurring iron-magnesium silicate with general formula of $\left(\mathrm{Fe}^{2+}, \mathrm{Mg}^{2+}\right)_{2} \mathrm{SiO}_{4}$. Olivine is applied in pilot plants and demonstration biomass gasifiers, such as the Güssing [1], Senden [2], Oberwart [3], and GoBiGas [4] plants. While olivine in its natural state has limited catalytic properties, its catalytic activity progressively increases with exposure to biomass ash [5]. During this activation process, an active ash layer is formed, which is rich in calcium (Ca) [6] and can also contain potassium (K) depending on the activation process applied [7]. The ash-coated olivine has catalytic activities towards tar reactions, which has been shown for different olivine materials and activation processes [1, 5, 8-11]. However, the reaction pathways that lead to tar reduction with in-bed catalysts in gasifiers, as well as the nature of the catalytic interactions are not well-understood, and the situation is further complicated by a combination of catalytic effects. For instance, catalytic tar reduction by ash-coated olivine has been attributed to the heterogeneous catalytic effects by Ca [1] and mixed oxides of Ca and K [7], as well as to gaseous potassium released from the ash-layer in the gasifier [5].

Homogeneous gas-phase catalytic interactions have so far attracted little attention in gasification literature, e.g. $[12,13]$. However, the mechanisms of polycyclic aromatic hydrocarbon (PAH) formation are understood in terms of the chemistry of gas-phase radicals 
[14-16], so it is likely that the ash-coated olivine can alter the gas-phase chemistry both indirectly, as a result of heterogeneous catalysis [11], as well as directly owing to the inhibitory effects of alkali on the formation of tar and soot $[12,13]$. Based on the existing literature [11, 12, 17-19], Figure 1 depicts the potential interplays between heterogeneous (lower box) and homogeneous (upper box) interactions between the ash-layered olivine and the tar chemistry.

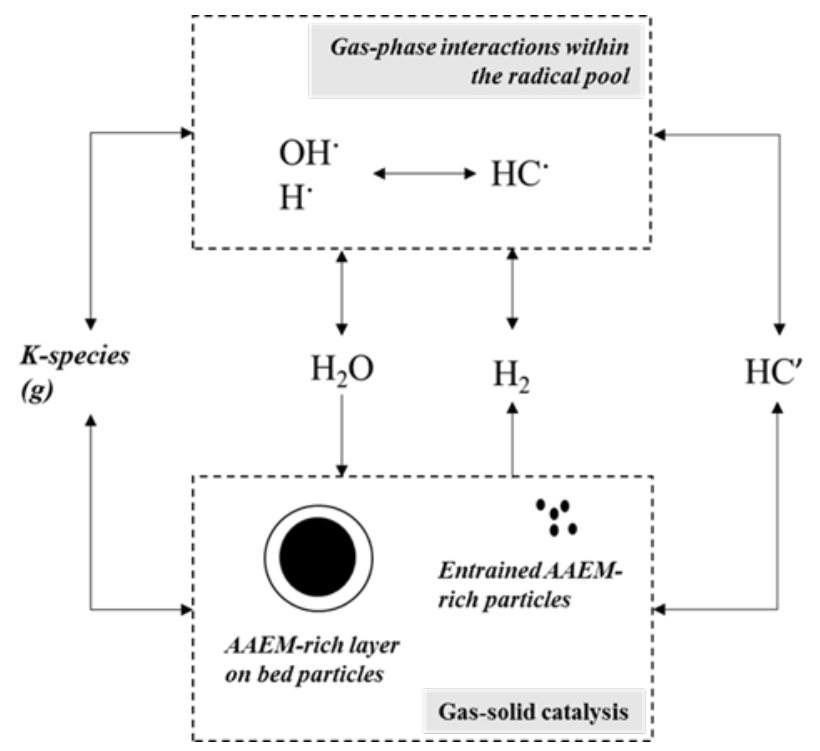

Figure 1. Potential interactions of alkali and alkali earth metals (AAEM) in the ash layer with the tar chemistry in the steam gasification environment, as elaborated from descriptions in [11, 12, 17-19] . HC' represents a generic hydrocarbon, and HC' represents a generic hydrocarbon radical.

The inhibitory effects of alkali on tar and soot formation have been attributed to reactions of the hydrogen and hydroxyl radicals with $\mathrm{KOH}$ and atomic $\mathrm{K}[19,20]$. In a recent study, Jiang et al. [17] showed that $\mathrm{K}$ activates gas-phase reactions that involve steam and cellulose-derived vapors. Their experiments were carried out with K-enriched steam and cellulose-derived vapors in the temperature range of $500^{\circ}-900^{\circ} \mathrm{C}$, conditions that mimic the gas environment in a gasifier with ash-coated olivine as the bed material and wood as the fuel. A higher concentration of $\mathrm{K}$ in the steam resulted in a higher yield of permanent gases, which is in agreement with previous experiments carried out with K- and Ca-enriched cellulose [21-23]. In the cases of lignin and hemicellulose pyrolysis, the literature is more scarce and 
inconclusive. When alkali metals influence the product distribution, higher yields of carbon oxides and lighter hydrocarbons are observed for both hemicellulose [24, 25] and lignin [26].

Kuba and coworkers [11, 27] have demonstrated the heterogeneous catalytic activity of ashcoated olivine towards steam reforming of 1-ring and 2-ring aromatics, more specifically, toluene and indene. Steam reforming of the tar precursor indene prevents its polymerization into chrysene [11]. The catalytic activity of olivine is also known to yield higher concentrations of $\mathrm{H}_{2}$, not only through tar reforming but also through catalytic steam gasification [28] and the water-gas shift reaction [27]. $\mathrm{H}_{2}$ also exerts inhibitory effects on tar and soot formation, probably related to the passivation of radicals, as has been reported in several contexts, e.g., combustion [29, 30], hydrocracking [31], and a steam $/ \mathrm{H}_{2}$ environment relevant to steam gasification [18, 32].

The results of Kuba et al. indicate that ash-coated olivine prevents the formation of PAHs in gasifiers by steam reforming the already formed monoaromatic [27] and PAH [11] tar species (routes 2 and 3 in Figure 2). With in-bed catalysts, the catalytic steam reforming of earlier tar precursors (homogeneous and/or heterogeneous catalysis) may also play a role in the prevention of formation of aromatics (route 1 in Figure 2). To the best of our knowledge, the conversion of earlier biomass-tar precursors in the presence of ash-coated materials has not yet been addressed in the literature. Corella et al. [33] first suggested that the potent effectiveness of in-bed catalysts is related to the prevention of maturation of the nascent tar vapors, in line with route $1 \mathrm{~b}$ in Figure 2. However, this hypothesis could not be tested due to the lack of a detailed characterization of the tar composition. 


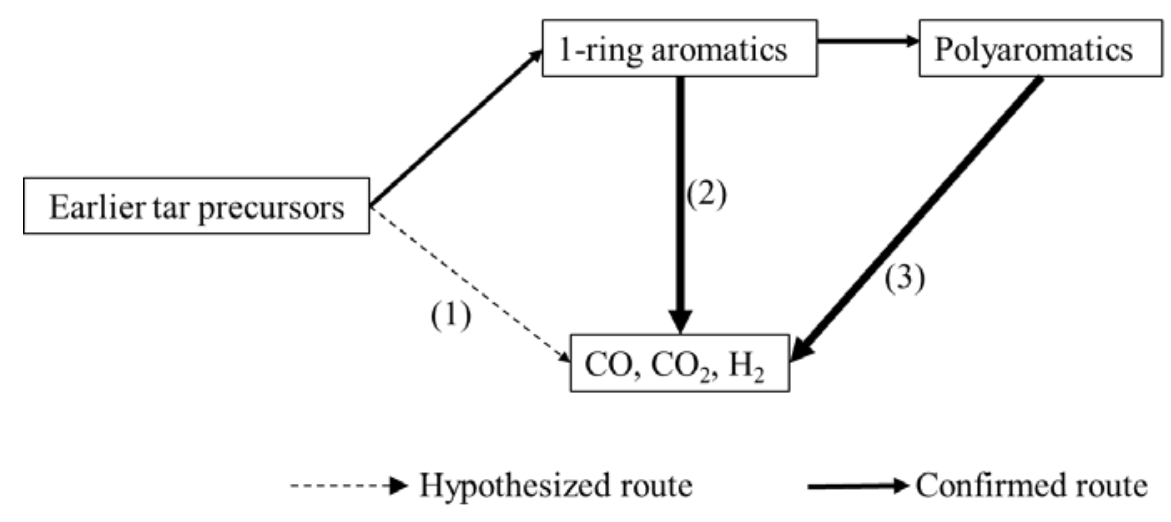

Figure 2. Potential routes for the prevention of the formation of polyaromatics (PAHs) at different stages of the formation of tar compounds, during biomass gasification with in-bed catalysts. in-bed catalysts. Route 1 hypothesized in [33]. Routes 2 and 3 confirmed in [11, 27].

The aim of the present work was to show that, when applied as an in-bed catalyst, ash-coated olivine prevents the formation of aromatic hydrocarbons at an early stage of tar formation, i.e., according to route $1 \mathrm{~b}$ in Figure 2. To understand better the influence of the ash-coated olivine on the evolution of the tar species, biomass gasification tests were carried out at various stages of the activation of the olivine, i.e., during ash layer formation process. The temperature of the reactor was varied over a range of relatively mild temperatures, i.e., $700^{\circ}-850^{\circ} \mathrm{C}$, to favor earlier tar precursors and with the aim of examining the behavior of the tar in the presence of an in-bed catalyst. The emphasis was on closing the carbon balance and testing the reproducibility of the results, so as to obtain reliable conclusions regarding the evolution of the tar species and the influence of the ash layer.

\section{Theoretical background}

The yields of the minor hydrocarbons species, which include monoaromatics (benzene and derivatives thereof), PAH species, earlier tar precursors, and light hydrocarbons $\left(\mathrm{CH}_{4}\right.$ and $\mathrm{C}_{2}$ 3), are reported in this work. Based on previous studies [14-16, 25, 32, 34-38], the expected evolution of the different minor hydrocarbon species with thermal severity, as well as the sources of the different species are summarized in Figure 3. The red-shadowed area in Figure 
3 includes the species that are here referred to as 'earlier tar precursors'. They include substituted phenols derived from lignin [34], cellulose- and hemicellulose-derived nonaromatic oxygenated compounds [25, 37], and 5-membered aromatic-rings, such as furan and furfural $[25,36]$.

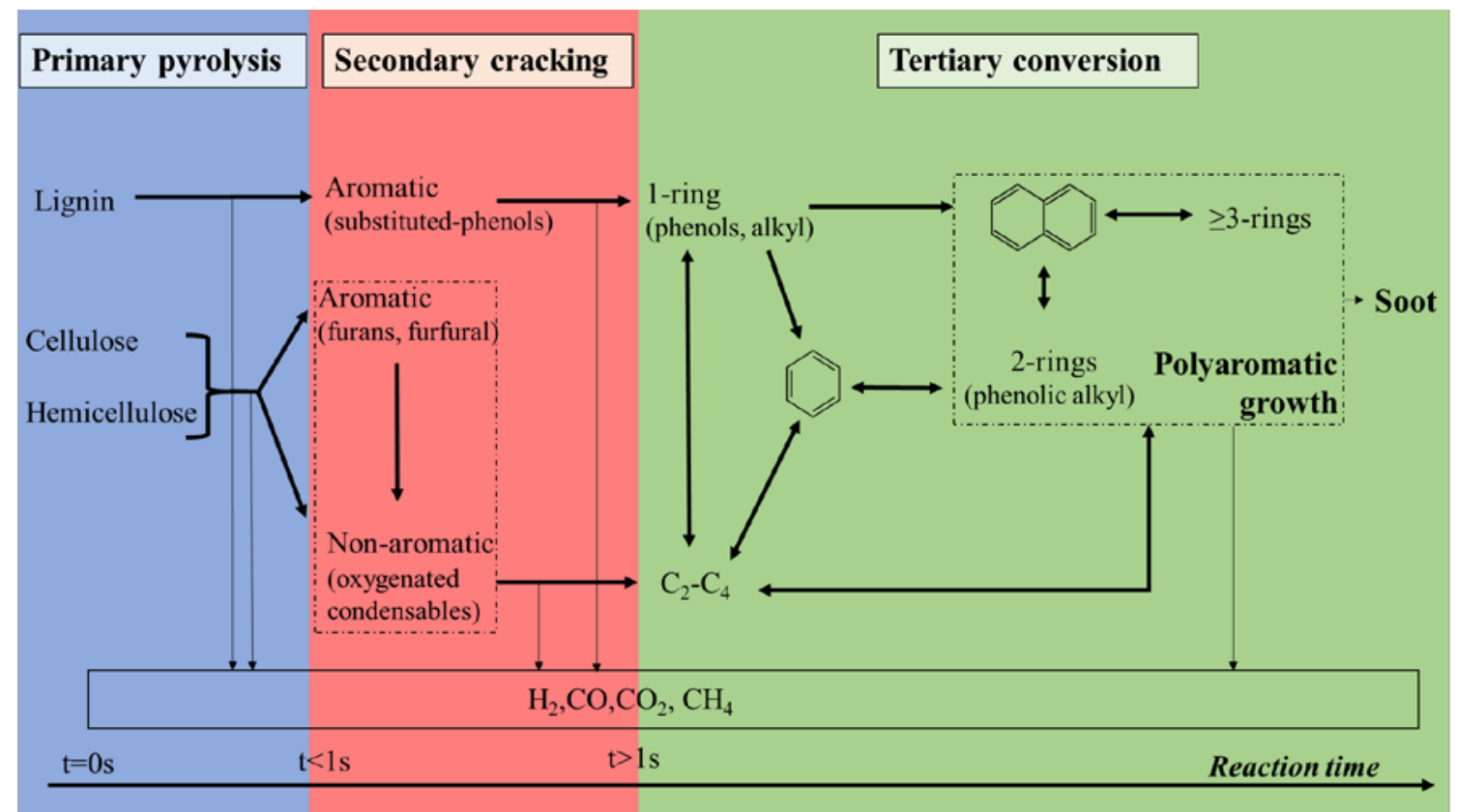

Figure 3. Simplified overview of the main transformations of biomass-derived condensable species during steam gasification of biomass at temperatures relevant to DFB gasifiers, i.e., $750^{\circ}-900^{\circ} \mathrm{C}$. Elaborated from descriptions in the literature [14-16, 25, 32, 34-38]. For simplicity, a limited number of representative species and tar growth mechanisms are shown.

Thermal severity and composition of minor hydrocarbons. The thermal severity (i.e., temperature and residence time) determines the nature of the tar exposed to the bed material and the types of species that are favored, according to the tar maturation scheme [39]. The lower the temperature, the more predominant are the earlier tar precursors. Investigations carried out with mild gasification temperatures $\left(<820^{\circ} \mathrm{C}\right)$ have shown that olivine is more active towards the conversion of phenols than other aromatic species $[1,5]$, which may be related to the ability of olivine to catalyze the dehydroxylation of phenol in the presence of $\mathrm{H}_{2}$ [38]. This reaction would, thereby, produce benzene in amounts corresponding to the phenol conversion. 
As the temperature increases, production of the non-substituted aromatics and PAHs is favored [39]. This shift in the tar composition occurs regardless of the catalytic activity of the bed material. For instance, in laboratory- and pilot-scale plants, increasing the temperature (within the range of $750^{\circ}-880^{\circ} \mathrm{C}$ ) during biomass gasification with an olivine bed (with [10] and without $[40,41]$ an ash layer) led to increased yields of non-substituted aromatics, i.e., naphthalene, acenaphthylene, and anthracene, whereas the yields of phenols and indene decreased. Recently obtained results from the gasifiers in Senden and Oberwart support these general trends [42]. Accordingly, the compositions of the tars at the exits of the gasifiers that operate within the typical temperature range of commercial units, i.e., $820^{\circ}-880^{\circ} \mathrm{C}$, are dominated by PAHs, with naphthalene as the major species [2, 4], followed usually by indene as the second most-dominant 2-ring aromatic [1, 2]. Benzene is seldom reported on in the gasification literature. However, when quantified, its yield is 3-5-fold that of naphthalene [4, 43] and the yield of benzene increases at higher temperatures [44, 45].

For a wide range of biomasses, Neves et al. [46] have shown overall increases in the yields of light hydrocarbons with increasing temperature. Typically, $\mathrm{CH}_{4}$ and $\mathrm{C}_{2} \mathrm{H}_{4}$ are the most abundant light hydrocarbons derived from biomass [5, 10, 40, 41, 46], while $\mathrm{C}_{2} \mathrm{H}_{6}, \mathrm{C}_{2} \mathrm{H}_{2}$ and $\mathrm{C}_{3}$ species are found in minor quantities and they are seldom discussed in the literature [43, 44, 47]. For steam gasification of wood, Zhang et al. [43] found increasing trends with temperature for $\mathrm{CH}_{4}, \mathrm{C}_{2} \mathrm{H}_{4}$, and $\mathrm{C}_{2} \mathrm{H}_{2}$; the yields of $\mathrm{C}_{3}$ and $\mathrm{C}_{2} \mathrm{H}_{6}$ were not discussed. Fuentes Cano et al. $[44,47]$ have shown for sewage sludge and pruning waste that at temperatures above $700^{\circ} \mathrm{C}$ the yields of $\mathrm{C}_{2} \mathrm{H}_{6}$ and $\mathrm{C}_{3}$ decrease with temperature.

Sources of minor hydrocarbons in biomass gasification. The production of light hydrocarbons from biomass is attributed to the decomposition of oxygenates, methoxy groups, and aliphatic side-chains [43]. For instance, in the temperature range of $700^{\circ}-1000^{\circ} \mathrm{C}$, the correlation between benzene and methane with increasing temperature has been explained in 
terms of the demethylation of toluene [48]. While benzene and naphthalene ring-opening reactions may also contribute to the formation of light hydrocarbons, this requires temperatures $>1000^{\circ} \mathrm{C}$ in the absence of a catalyst $[18,32]$. Therefore, under the conditions applied in this work $\left(700^{\circ}-850^{\circ} \mathrm{C}\right)$, ring-opening reactions are mainly expected under catalytic conditions.

Benzene can be formed through the dealkylation of alkyl-aromatics [32, 36] and the dehydroxylation of phenol [35, 38]. However, Israelsson et al. [45, 49] have reported that at temperatures $<830^{\circ} \mathrm{C}$, the conversion reactions of toluene and phenol are not sufficient to explain the high yields of benzene obtained with an increase in process temperature. Similarly, Fuentes Cano et al. [44] observed a net increase in the levels of aromatic compounds with increasing residence time, whereby the most significant increase was for monoaromatic hydrocarbons [44]. Their results confirm the existence of a fraction of earlier tar precursors, which were not identified by the quantification methods applied, but which represented a source of aromatic compounds [44, 45]. In the work of Israelsson et al. [49], this fraction was labeled as Unidentified Condensable Species (UCS), and its share of the carbon balance was estimated by means of a High-Temperature Reactor (HTR) [50], which is used in this work for the same purpose.

Based on the detailed characterization of the pyrolysis products made by Zhang et al. [43] and Morf et al. [51], the UCS fraction at the temperature applied in this work $\left(<850^{\circ} \mathrm{C}\right)$ is likely to be rich in compounds with molecular weights lower than that of benzene. For this fraction to convert into benzene rings, the recombination of carbon-containing species is required. Cypress [52] has demonstrated that short-chain olefins can contribute to the formation of both monocyclic and polycyclic aromatics, which is attributed to the Diels-Alder reactions involving $\mathrm{C}_{4} \mathrm{H}_{6}$ and $\mathrm{C}_{3} \mathrm{H}_{6}$. Other precursors for aromatic ring formation are $\mathrm{C}_{2} \mathrm{H}_{2}$ through cyclotrimerization [14], as well as the cyclodimerization of $C_{3}$ hydrocarbons, which usually 
involves the propargyl radical [36]. These routes to the formation of benzene require that the UCS fraction is first converted into $\mathrm{C}_{2}-\mathrm{C}_{4}$ hydrocarbons.

The 2-ring species and heavier PAHs are formed by tar growth mechanisms that are dependent upon the availability of PAH precursors. Extensive aromatic growth is thought to result in soot formation [14], as indicated in the right-hand side of Figure 3. The most common mechanisms described in the gasification literature for aromatic growth are: (1) the $\mathrm{H}_{2}$-abstraction/ $\mathrm{C}_{2} \mathrm{H}_{2}$ addition (HACA) mechanism [14]; and (2) a sequence of cyclopentadiene [15] / indene [16] additions. The cyclopentadienyl radicals involved in the second mechanism are thought to be produced by decarboxylation of phenols [14] or by the recombination of $\mathrm{C}_{3} \mathrm{H}_{6}$ with $\mathrm{C}_{2} \mathrm{H}_{2}$ [36]. The latter route enables the formation of PAHs without prior formation of a monoaromatic species.

\section{Experimental section}

Description of the Chalmers dual fluidized bed system. The experiments presented here were carried out in the Chalmers DFB gasifier. The plant consists of a $12-\mathrm{MW}_{\text {th }}$ circulating fluidized bed (CFB) boiler that is interconnected to a 2-4-MW th bubbling bed gasifier (Figure 4). The DFB system hosts approximately 3 tonnes of bed material, which circulates between the boiler and the gasifier. Fuel is fed to the CFB boiler continuously during the winter season to provide heat to the campus, while the gasifier is operated with fuel only when gasification research activities take place. Continuous gasification runs are limited to $12 \mathrm{~h} / \mathrm{day}$ (6 am to 6 $\mathrm{pm}$ ) during weekdays owing to permit conditions. This means that during the nights and weekends, fuel is fed only to the boiler side.

The bed material used is olivine of Norwegian origin, the composition (as received) of which is listed in Table 1. During the gasification experiments, the gasifier side is fluidized with steam and fuel is fed simultaneously to both reactors: wood pellets to the gasifier and wood chips to 
the combustor. The compositions of the fuels are summarized in Table 2. The results presented here correspond to the gasifier side. The flows of fuel and steam applied in the gasification experiments are $300 \mathrm{~kg} / \mathrm{h}$ and $160 \mathrm{~kg} / \mathrm{h}$, respectively. The fuel is fed to the gasifier by gravity from the top of the reaction as indicated in Figure 4 (position 14). According to a previous investigation [53], this gasifier configuration is expected to limit the fraction of volatiles that meets the bed material to roughly half. The flow of fuel to the boiler side is $1-2$ tonnes/h depending on the operational conditions applied.

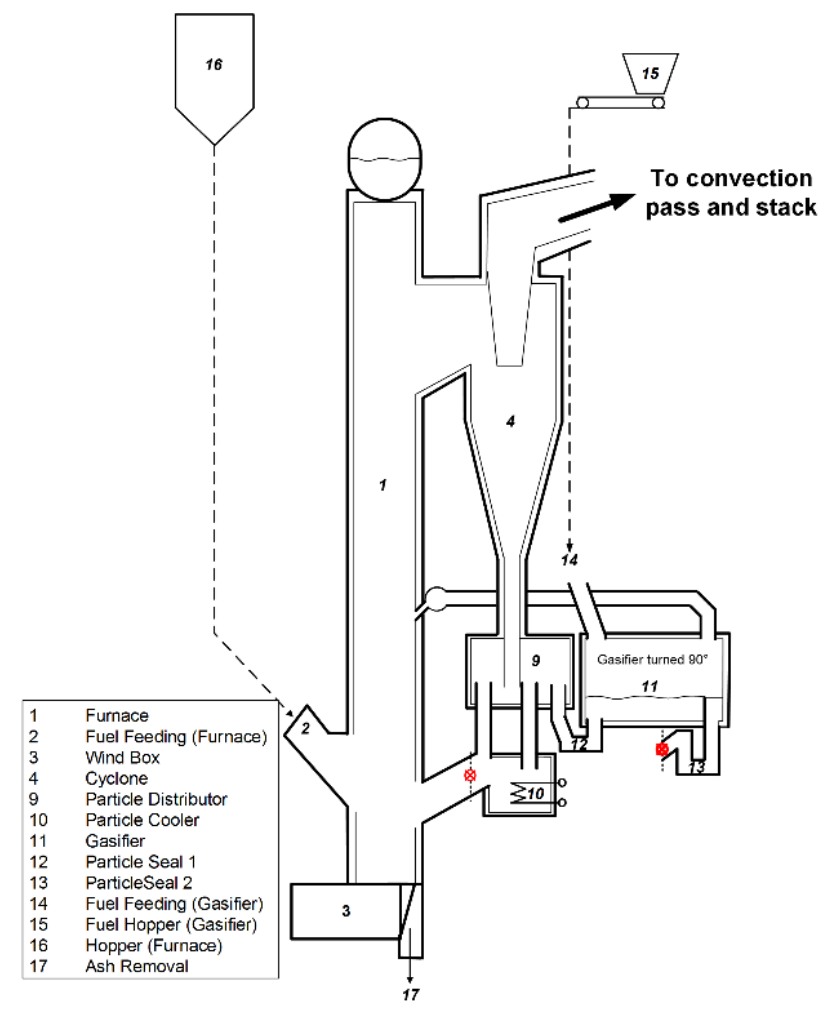

Figure 4. Schematic of the Chalmers DFB gasifier.

Table 1. Composition of the Norwegian olivine, as received.

\begin{tabular}{ll}
\hline Metal oxide & Olivine sand \\
\hline $\mathrm{SiO}_{2}$ & 41.7 \\
$\mathrm{Al}_{2} \mathrm{O}_{3}$ & 0.46 \\
$\mathrm{Fe}_{2} \mathrm{O}_{3}$ & 7.4 \\
$\mathrm{MgO}$ & 49.6 \\
$\mathrm{Cr}_{2} \mathrm{O}_{3}$ & 0.31
\end{tabular}


Table 2. Compositions of the wood pellets as fed to the gasifier and of the wood chips as fed to the boiler.

\begin{tabular}{llll}
\hline Parameter & $\begin{array}{l}\text { Wood pellets } \\
\text { (gasifier) }\end{array}$ & $\begin{array}{l}\text { Wood chips } \\
\text { (boiler) }\end{array}$ & Unit \\
\hline $\mathrm{C}$ & $50-51$ & $49-50$ & mass\% db \\
$\mathrm{H}$ & $6.0-6.2$ & $6.0-6.2$ & mass\% db \\
$\mathrm{O}$ & $43-44$ & 43 & mass\% db \\
$\mathrm{N}$ & $0.05-0.06$ & $0.11-0.13$ & mass\% db \\
$\mathrm{S}$ & $<0.02$ & $<0.02$ & mass\% db \\
LHV & $18.9-18.5$ & $18.7-18.3$ & MJ/kg db \\
Ash & $0.4-0.5$ & $0.5-0.7$ & mass\% db \\
Moisture & $7-9$ & $36-46$ & mass\% \\
\hline
\end{tabular}

Experimental matrix. The experiments are divided into four experimental series, and the operating conditions of the gasifier in each experimental series are summarized in Table 3. The experimental series differ in relation to the catalytic activity of the bed material applied: Reference Silica Sand; Low-Activity Olivine; Active Olivine (no additives); and Active Olivine (alkali-enriched). The aim is to create an arbitrary scale of catalytic activity, wherein the catalytic effects are minimized in the Reference-Silica Sand series and maximized in the Active Olivine series. The relative catalytic activities of the bed materials corresponding to the different experimental series are ranked according to the tar yields measured (later shown in the Results Section).

The Reference Silica Sand series corresponds to the previously published tests [49] with silica sand in the Chalmers gasifier. The Low-Activity Olivine series corresponds to an experiment with a bed of olivine approximately 24-48 h after the start-up with a batch of untreated material. At that stage, the cumulative input of fuel ash to the system was less than $200 \mathrm{~kg}$ and the ash layer formation was ongoing. The Active olivine (no additives) series includes cases in which the olivine was activated without the application of additives, i.e., the formed ash layer 
originates exclusively from the fuel ash. At that stage, the cumulative input of ash with the fuel is $>800 \mathrm{~kg}$. The Active olivine (ash-enriched) series includes gasification experiments with olivine that was activated with alkali addition by recirculation of the fly ash into the system (as reported in [54]) and by the addition of S and $\mathrm{K}$ (as reported in [8]), respectively. For detailed analysis of the different bed materials applied, the reader is referred to separate publications, i.e. $[5,28,54]$.

Table 3. Experimental cases and operating conditions of the gasifier.

\begin{tabular}{lllll}
\hline Series & Bed material & $\begin{array}{l}\text { Steam-to- } \\
\text { fuel ratio } \\
\mathbf{k g} / \mathbf{k g ~ d a f})\end{array}$ & $\begin{array}{l}\mathbf{T}_{\text {bed }} \\
\left({ }^{\circ} \mathbf{C}\right)\end{array}$ & $\begin{array}{l}\mathbf{T}_{\text {freeboard }} \\
\left({ }^{\circ} \mathbf{C}\right)\end{array}$ \\
\hline $\begin{array}{l}\text { Reference Silica Sand } \\
\text { (adopted from ref [49]) }\end{array}$ & Silica sand & 0.8 & $786-823$ & $723-749$ \\
$\begin{array}{l}\text { Low-Activity Olivine } \\
\begin{array}{l}\text { Active Olivine (no } \\
\text { additives) }\end{array}\end{array}$ & Olivine sand & 0.8 & $768-848$ & $727-794$ \\
$\begin{array}{l}\text { Active Olivine (ash- } \\
\text { enriched) }\end{array}$ & Olivine sand & 0.8 & $762-817$ & $718-759$ \\
\hline
\end{tabular}

In addition, tests were carried out at different gasifier temperatures for each level of catalytic activity and covering a similar range of temperatures, i.e., a specific temperature was not targeted. The aim here was to produce conditions under which the primary and tertiary tar species, respectively, were favored. During the $12 \mathrm{~h} /$ day of continuous operation of the gasifier, the operating conditions could be changed several times. Typically, up to 4 steady state cases (at different temperatures) could be recorded in a day, and each steady state was held for approximately 1 hour.

Combined measurements. To characterize the raw gas composition, a combination of measurements was applied to two parallel slipstreams (schematized in Figure 5). The tar and permanent gas compositions are sampled from slipstream 1. Tar is sampled using the SPA- 
method, as described below. Downstream of the tar sampling position, slipstream 1 is quenched with isopropanol to condense the moisture and remove the tar, then further cooled and led to a gas chromatograph $(\mu-\mathrm{GC} 1)$.

Slipstream 2 is used for quantification of the total carbon in the hot gas by means of a HTR that was developed in a previous work [50] as a tool to close the carbon balance. In the HTR, slipstream 2 is fully converted into $\mathrm{H}_{2}, \mathrm{CO}, \mathrm{CO}_{2}$ and $\mathrm{H}_{2} \mathrm{O}$ by heating the gas to $1700^{\circ} \mathrm{C}$. The fully reformed gas at the exit of the HTR is analyzed in a gas chromatograph ( $\mu$-GC 2) prior to filtering and cooling, as shown in Figure 5.

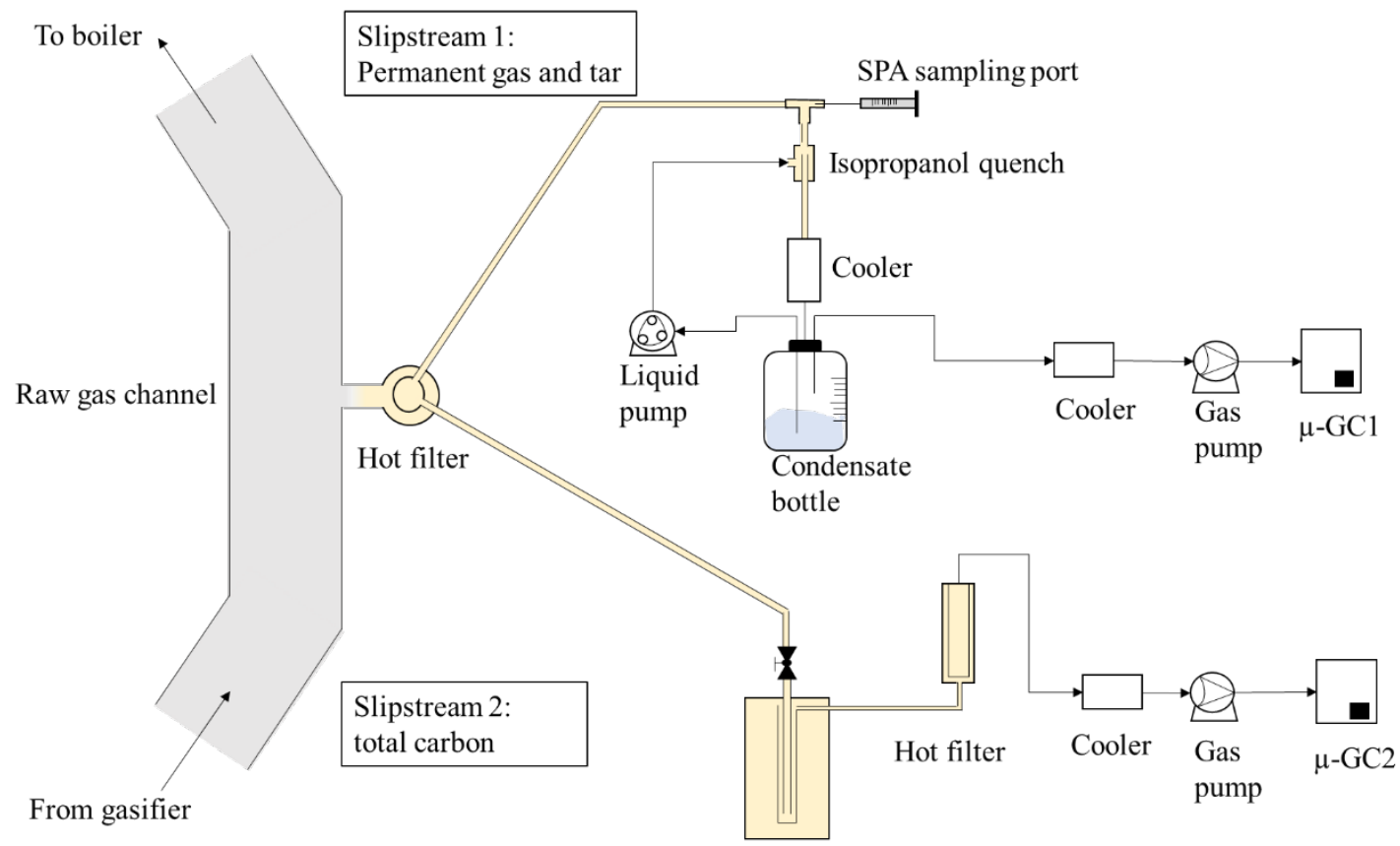

High Temperature Reactor

Figure 5. Simplified schematic of the gas sampling system, including the two parallel slipstreams, and the sampling position for the SPA-method. The colored lines are heat-tracer lines at $350^{\circ} \mathrm{C}$; the remainder of the piping corresponds to the cold sides of the slipstreams.

Analysis of the permanent gases and HTR gas. The two gas chromatographs applied for the analysis of slipstreams 1 and 2 ( $\mu$-GC1 and $\mu$-GC2) are the Varian CP-4900. The $\mu-G C 1$ is equipped with a PoraPlotQ and an MS $5 \AA$ column, using He and Ar as the carrier gases,

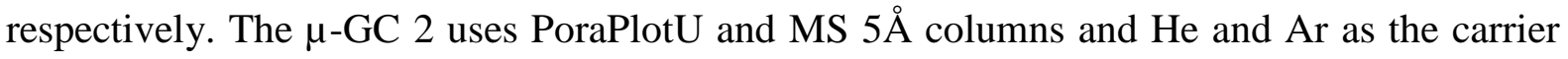


gas, respectively. The assayed species, which are divided into the groups applied in the Results section, are summarized in Table 4.

Quantification of gas yield. The total flow of dry raw gas produced in the gasifier is quantified with the help of a tracer stream of He, as explained elsewhere [55]. The He is mixed with the fluidization steam before entering the gasifier. The He flow is set at $20 \mathrm{Ln} / \mathrm{min}$ in the Bronkhorst ${ }^{\circledR}$ model F-202AV mass flow controller, yielding a He concentration in the raw gas that falls within the calibration levels of the two $\mu$-GCs, typically $0.2 \%-1.0 \%$ vol (dry basis) .

SPA-method. Aromatic species with boiling points between those of benzene and chrysene are quantified according to the solid-phase adsorption (SPA) method [56, 57]. A raw gas sample of volume $100 \mathrm{~mL}$ is forced through an adsorption column. The adsorbent column is the Supelclean ENVI-Carb/NH2 (Sigma-Aldrich), which contains a layer of $500 \mathrm{mg}$ of aminopropyl-bonded silica, followed by a layer of $500 \mathrm{mg}$ of active carbon. The silica layer adsorbs efficiently hydrocarbons that are heavier than phenol, while the carbon layer ensures the adsorption of lighter species, such a benzene, toluene, and xylene (BTX) [49].

The SPA-samples are rinsed twice with an eluent, generating a first sample vial and a control vial. The control vial is used to verify that all the hydrocarbons have been desorbed in the first rinse. The resulting liquids are analyzed three times in a gas chromatograph. The results in the three chromatograms derived from each vial are averaged, and the two average values (sample and control) are summed. Each chromatogram involves $1 \mathrm{~h}$ of analysis.

The gas chromatograph is equipped with the BRUKER-430 flame ionization detector (GCFID), which uses $\mathrm{H}_{2}$ as the carrier gas and a BR-17ms column (30 $\mathrm{m} \times 0.25 \mathrm{~mm}$, fused silica). The instrument is calibrated for 28 tar species, which are summarized and sorted by the groups applied in this work (Table 4). The accuracy of the instrument is tested after every set of samples by analyzing a known solution, i.e., a randomly chosen calibration level. If the results 
for the known solution deviate by more than $10 \%$ (rel) from the corresponding calibration point, the instrument is recalibrated.

All the chromatograms showed peaks that corresponded to species for which the instrument was not calibrated, representing $2 \%-20 \%$ of the detected mass, depending on the case. Educated guesses as to the molecular weights of these species can be made according to their locations on the chromatograms. However, their structures (alkyl, phenol, condensed etc.) are unknown and they are, therefore, treated as a separate group (Table 4).

Table 4. Carbon-containing species assayed and sorted by groups according to the carbon balance calculations.

\begin{tabular}{|c|c|c|}
\hline & Group & Assayed C-containing species \\
\hline \multirow[t]{4}{*}{ Permanent gas } & CO: & $\mathrm{CO}$ \\
\hline & $\mathrm{CO}_{2}:$ & $\mathrm{CO}_{2}$ \\
\hline & $\mathrm{CH}_{4}:$ & $\mathrm{CH}_{4}$ \\
\hline & $\mathrm{C}_{2}-\mathrm{C}_{3}:$ & $\mathrm{C}_{2} \mathrm{H}_{2}, \mathrm{C}_{2} \mathrm{H}_{4}, \mathrm{C}_{2} \mathrm{H}_{6}, \mathrm{C}_{3} \mathrm{H}_{6}, \mathrm{C}_{3} \mathrm{H}_{8}$ \\
\hline \multirow{8}{*}{$\begin{array}{l}\text { SPA-measurable } \\
\text { tars }\end{array}$} & Benzene: & benzene \\
\hline & 1-ring: & toluene, o/p-xylene, styrene, methyl-styrene \\
\hline & Naphthalene: & naphthalene \\
\hline & 2-rings: & $\begin{array}{l}\text { indene, 1,2-dihydronaphthalene, } \\
\text { 1-methylnaphthalene, 2-methylnaphtalene, biphenvl }\end{array}$ \\
\hline & 23-rings: & $\begin{array}{l}\text { acenaphthylene, acenaphthene, fluorene, } \\
\text { phenanthrene, anthracene, xanthene, fluoranthene, } \\
\text { pyrene, chrysene }\end{array}$ \\
\hline & Phenols: & phenol, o/p-cresol, 1-naphtol, 2-naphtol \\
\hline & Furans: & benzofuran, dibenzofuran \\
\hline & SPA-Unknowns & $\begin{array}{l}\text { Species for which the instrument was not calibrated } \\
\text { but for which corresponding peaks are observed in } \\
\text { the chromatograms }\end{array}$ \\
\hline $\begin{array}{l}\text { Unidentified } \\
\text { condensable } \\
\text { species }\end{array}$ & UCS: & $\begin{array}{l}\text { Species not detected by the SPA-method, likely with } \\
\text { molecular weights that are lower than that of benzene } \\
\text { and that are not measured in the permanent gas } \\
\text { analysis }\end{array}$ \\
\hline
\end{tabular}

Quantification of total condensable and unidentified condensable species (UCS). The carbon that exits the gasifier in the form of condensable species $\left(n_{C, \text { cond }}\right)$, and the fraction of 
the condensable species that consists of unidentified compounds $\left(n_{C, U C S}\right)$ are calculated by difference based on the carbon balance [50], and according to Equation 1-3.

$$
\begin{array}{ll}
n_{C, \text { cond }}=n_{C, H T R}-n_{C, P G} & \text { Equation } 1 \\
n_{C, U C S}=n_{C, H T R}-n_{C, P G}-n_{C, S P A} & \text { Equation 2 } \\
n_{C, S P A}=n_{C, S P A-i d}+n_{C, S P A-u n k} & \text { Equation 3 }
\end{array}
$$

where $n_{C, H T R}$ refers to the yield of total carbon as measured by the HTR, $n_{C, S P A}$ is the yield of carbon measured by the SPA-method, and $n_{C, P G}$ is the yield of carbon in the permanent gases. Note that the carbon in the SPA-method $\left(n_{C, S P A}\right)$ includes the carbon in the identified species $\left(n_{C, S P A-i d}\right)$ and an estimate of the carbon in the unknown species $\left(n_{C, S P A-u n k}\right)$, as shown in Equation 3. The latter is calculated by assuming that the unknown compounds have similar molecular weights and carbon contents as the next identified species in the chromatogram. The ambition in accounting for as much carbon as possible in the chromatograms is that the SPAmeasurable tar should be a good representative value of the aromatic species with molecular weights higher than that of benzene. Accordingly, the UCS fraction obtained at the mild temperature applied in the present work is expected to be rich in earlier tar precursors [49], which are not aromatic, as well as 5-membered-ring compounds.

Closure of the carbon balance. The closure of the carbon balance with the HTR is estimated as $100 \% \pm 2 \%$. This is determined by the typical value of the standard deviation of the total carbon in the hot gas quantified using the HTR under stable conditions. The coverage of the combined measurements to characterize the raw gas composition was tested in a set of validation experiments (Figure 6), which have been described in other publications for a different purpose [49, 58]. 
In the validation tests, the total carbon measured by the HTR was compared to the sum of the carbon measured in the SPA and the permanent gas. Under specific operating conditions (active bed materials and $>810^{\circ} \mathrm{C}$ ), the SPA and permanent gas measurements were sufficient to characterize the total carbon in the raw gas within the standard deviation of the HTR measurement. With milder temperatures and inert bed materials, the closure of the carbon balance was poorer, indicating that UCS exist in quantities detectable by the methods applied [49].

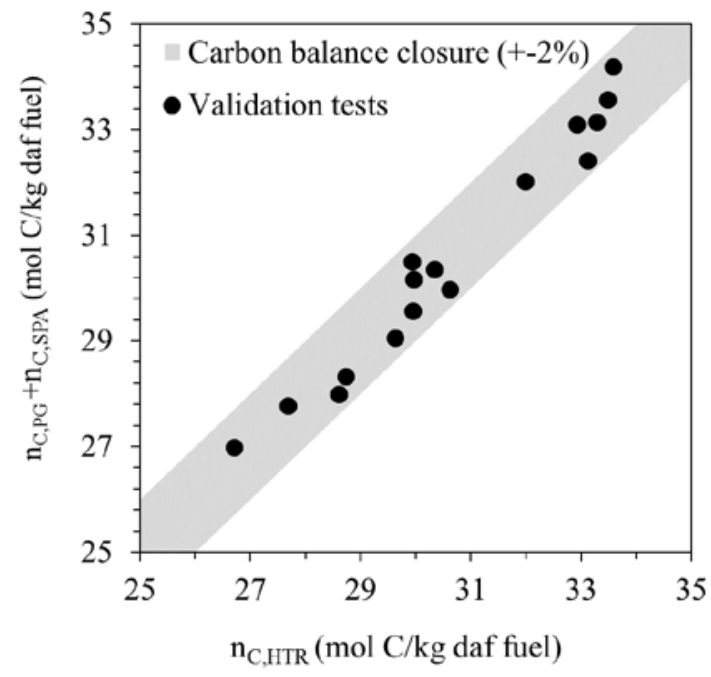

Figure 6. Examples of validation tests for the combined measurements applied in this work to quantify the carbon in the raw gas: SPA-measurable tar $\left(\mathrm{n}_{\mathrm{C}, \mathrm{SPA}}\right)$, permanent gas $\left(\mathrm{n}_{\mathrm{C}, \mathrm{PG}}\right)$, and an independent measurement of the total carbon in the hot raw gas $\left(\mathrm{n}_{\mathrm{C}, \mathrm{HTR}}\right)$ by means of a HTR. The analysis is based on experiments with biomass in a bed of silica sand and ilmenite, respectively, at a bed temperature $>810^{\circ} \mathrm{C}$, as reported previously $[49,58]$

Data evaluation and reproducibility of the results. Each experimental case was evaluated as the average value obtained over 30-60 minutes of sampling during steady-state operation, i.e., excluding variations due to changes in the operating conditions. The concentrations of permanent gases and those derived from the HTR were measured every 3 minutes throughout the sampling period, which entailed 10-20 chromatograms per stable case. Four SPA (repeat) 
samples were collected for each steady-state condition, entailed 24 chromatograms in the GCFID. The average values of the measurements were used for further mass balance calculations. In addition, the reproducibility of the results was tested by means of repeat experiments, which were carried out during several experimental campaigns (different years) and in different days within the same experimental campaign. In total, 37 experimental cases are evaluated in this work, which corresponds to approximately 130 hours of gasifier operation and 1000 hours of SPA analysis. Unless otherwise specified, the Results section shows the average and the standard deviation values of the repeat tests.

\section{Results}

Overview of the carbon balance. The carbon balances for selected experiments are summarized in Figure 7. The corresponding molar yields of $\mathrm{H}_{2}$ are shown in the secondary axis. The carbon balance is shown as the percentage of the carbon from the fuel that leaves the gasifier as unconverted char, $\mathrm{CO}, \mathrm{CO}_{2}, \mathrm{CH}_{4}, \mathrm{C}_{2}-\mathrm{C}_{3}$ hydrocarbons, and condensable species. The condensable fraction includes both identified (SPA) and unidentified (UCS) condensable species, calculated according to Equation 1. Note that the operating temperature differs among experimental series in Figure 7.

An increase in bed temperature and/or catalytic activity results in a higher yield of permanent gases, at the expense of the yields of total condensable species (red bar in the figure) and char (black bar in the figure). Under similar operating conditions, the molar yields of $\mathrm{H}_{2}$ are higher with Active Olivine as compared to those derived from the use of silica sand and Low-Activity Olivine. Regarding the carbon oxides $\left(\mathrm{CO}+\mathrm{CO}_{2}\right)$, the shares of $\mathrm{CO}_{2}$ become larger as the catalytic activity increases. These trends are in line with a promoted Water-Gas-Shift reaction by the active olivine. The lower yield of $\mathrm{H}_{2}$ in the case of Active Olivine (ash-enriched) compared to the Active Olivine (no additives) can be the result of higher oxygen transport by 
the ash-enriched material. On the following, the focus will be the light hydrocarbons and tar fractions, which will be shown and discussed in detail.

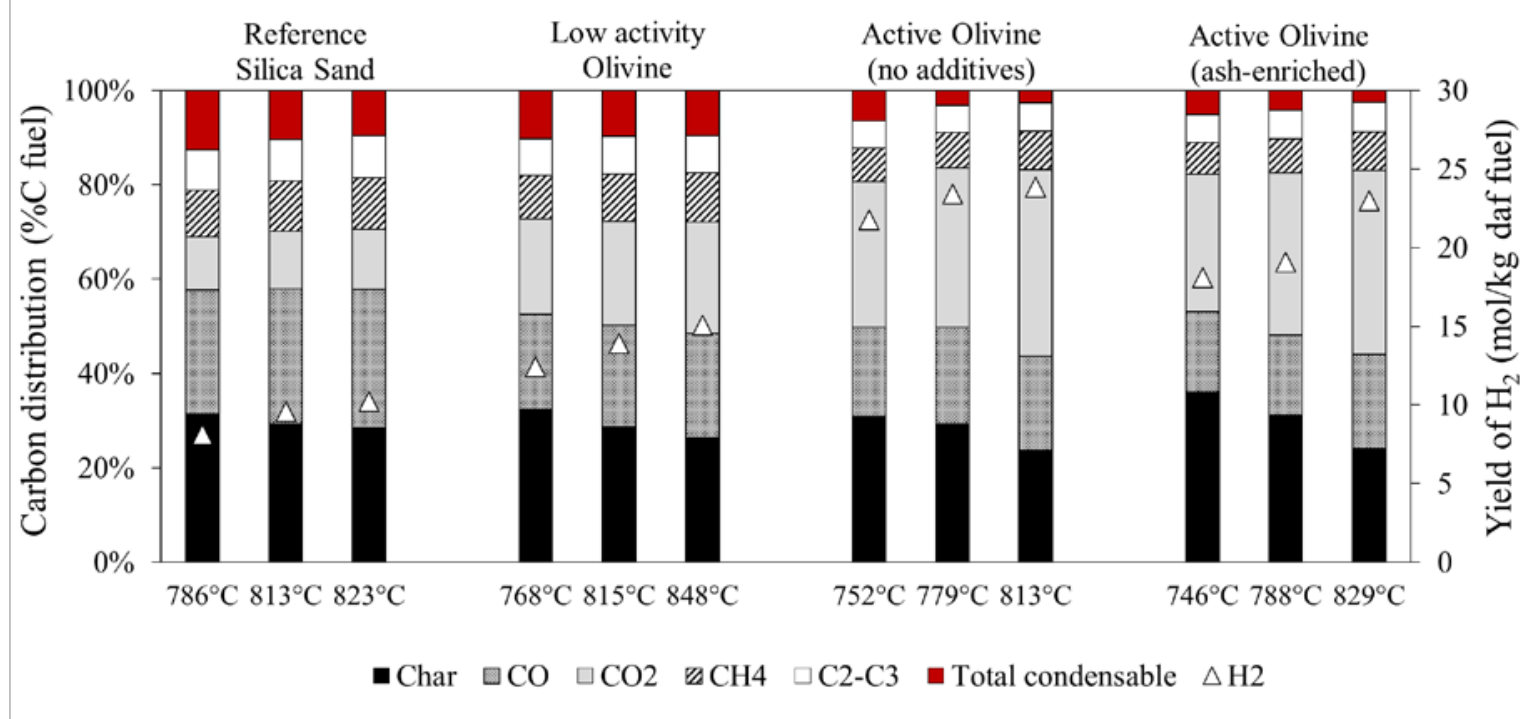

Figure 7. Yield of $\mathrm{H}_{2}$ (secondary axis), and distribution of carbon (primary axis) into gasification products. Wood pellets in the Chalmers gasifier, with $\mathrm{S} / \mathrm{F}=0.8$ and various bed temperatures. From left to right: reference cases with silica sand, series with olivine exhibiting low and high catalytic activity, with and without the help of additives, respectively.

Influence of increasing catalytic activity on the yields of minor hydrocarbons. The catalytic activity of olivine towards the condensable fraction is relevant to the entire range of temperatures investigated, i.e., $750^{\circ}-850^{\circ} \mathrm{C}$. In agreement with the results of previous studies with olivine $[5,8]$, the catalytic properties of olivine towards the condensable fraction is more pronounced for the olivine bed that has been exposed to biomass ash for a longer period of time (Active Olivine-no additives), and also for the olivine exposed to additives (Active Olivineash enriched). The results derived from the use of the olivine and additives (termed Active Olivine-ash-enriched in the figure) are similar to those obtained with the olivine that interacts with biomass ash only. The main difference is a slightly higher catalytic activity for the olivine with additives, as inferred from Figure 8 and Figure 9, which show cases with different catalytic activities and similar bed temperatures $\left(805^{\circ}-815^{\circ} \mathrm{C}\right)$. Each case shown in the figures 
represents the average of four repeat experiments, and the error bars indicate the reproducibility of the results, i.e., the standard deviation of the repeated tests. The differences between the repeats are likely related to the initial state of the DFB system and the status of the bed material at the time of the measurement. From these results, it is concluded that the ash-enriched olivine is an example of a higher activity level, at least for the arbitrary activation scale shown here.

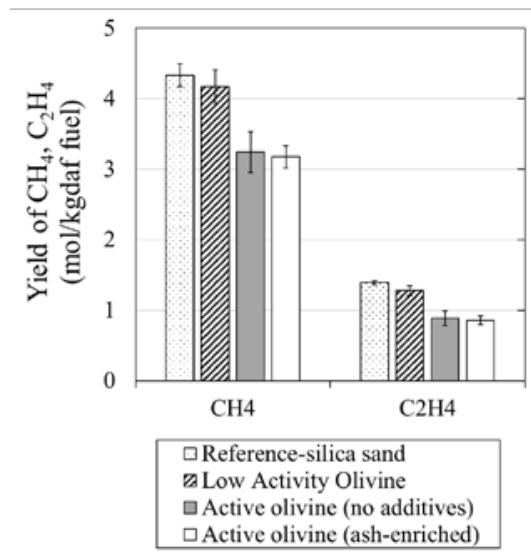

Figure 8. Yields of the most abundant hydrocarbons in the raw gas produced in the Chalmers gasifier at $810^{\circ} \mathrm{C}$ and $\mathrm{S} / \mathrm{F}$ ratio of 0.8 . Shown are the reference case with silica sand and olivine cases with different levels of activation. Each case represents the average of four repeat experiments.

As expected, the dominant light hydrocarbons in the raw gas are $\mathrm{CH}_{4}$ and $\mathrm{C}_{2} \mathrm{H}_{4}$. The yields of other $\mathrm{C}_{2}-\mathrm{C}_{3}$ species are one to two orders of magnitude lower than those of $\mathrm{CH}_{4}$ and $\mathrm{C}_{2} \mathrm{H}_{4}$, and lie within the same range of molar yields as that for the most abundant aromatic compounds. The most abundant aromatic compound is benzene, in line with previous findings $[4,43]$. The 2-ring aromatics are dominated by naphthalene, followed by indene, as also observed in other gasifiers [1, 2]. Increasing the catalytic activity results in lower yields of all the aromatic species quantified as well as a decrease of the yields of $\mathrm{CH}_{4}, \mathrm{C}_{2} \mathrm{H}_{4}$, and $\mathrm{C}_{2} \mathrm{H}_{2}$. The decrease in the level of $\mathrm{C}_{2} \mathrm{H}_{2}$ is comparatively more pronounced, which indicates a higher activity of olivine towards the conversion of this species. Furthermore, the $\mathrm{C}_{3}$ species are the only light hydrocarbon measured that are favored at higher catalytic activities. The relationship between 
the yield of $\mathrm{C}_{2} \mathrm{H}_{6}$ and the catalytic activity is unclear, and the highest yield of $\mathrm{C}_{2} \mathrm{H}_{6}$ measured corresponds to the Low-Activity Olivine case. The light hydrocarbon fraction is more saturated in the cases with olivine, i.e., the $\mathrm{H} / \mathrm{C}$ molar ratio of the $\mathrm{C}_{2}-\mathrm{C}_{3}$ fraction is $4-5$-fold higher in the cases with olivine than in the silica sand case.

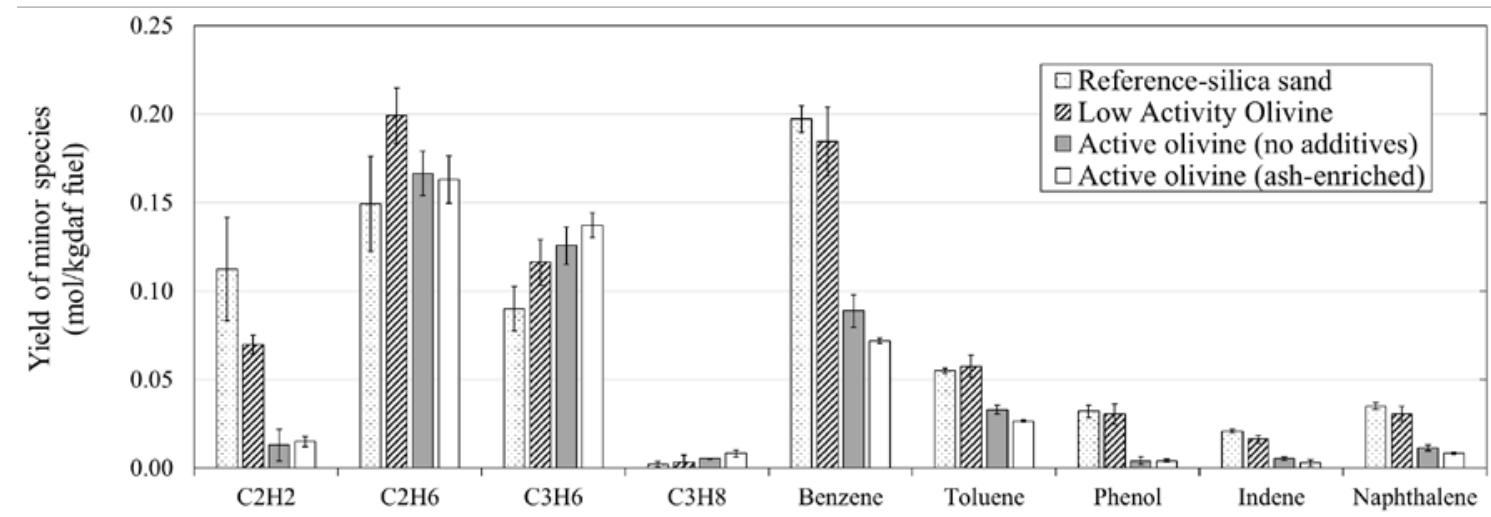

Figure 9. Yields of minor permanent gas species and predominant tar species in the raw gas produced in the Chalmers gasifier at a bed temperature of $810^{\circ} \mathrm{C}$ and $\mathrm{S} / \mathrm{F}$ ratio of 0.8 . Shown are the reference case with a bed of silica sand and three cases with olivine at different levels of activation. Each case represents the average of four repeats experiments.

Overall, the trends observed for the light HCs are the opposite of those expected for increasing thermal severity $[43,44]$, which anticipates that different conversion mechanisms are enabled by olivine, as compared to those related to the non-catalyzed thermal conversion.

Influence of temperature on the yields of minor hydrocarbons. The temperature dependence of the yields of minor hydrocarbons is summarized in Figures 10-14. The results shown in Figure 10 are built on 23 experimental cases and show the composition of the condensable fraction $\left(n_{C, \text { cond }}\right)$ aggregated into SPA-measurable carbon $\left(n_{C, S P A}\right)$ and the carbon in the unidentified species $\left(n_{C, U C S}\right)$, respectively, for the cases with silica sand and with Active Olivine. The Active Olivine cases (with and without additives) are not differentiated in the figure on purpose, as the differences in terms of the carbon balance were limited. The detailed compositions of the SPA fraction and $\mathrm{C}_{1-3}$ hydrocarbons corresponding to each experimental 
series separately are shown in Figures 11-14. When repeat experiments are available, the results are shown as the average of the (3-5) repeated cases, and the error bars indicate the standard deviation of the average.

The SPA results showed good reproducibility, with standard deviations of $<20 \%$ (rel), i.e., $0.1-$ $0.3 \mathrm{molC} / \mathrm{kg}$ daf fuel. In contrast, the reproducibility of the UCS estimate was poorer, which is partially explained by the low yield of UCS combined with the accumulation of uncertainties related to the three parallel measurements (recall Equation 2 for estimation of the UCS). Most of the UCS values for the Active Olivine were lower than the absolute standard deviation of the total carbon quantified by the HTR, which meant that they were too low to be quantified accurately with the method applied. Some negative UCS yields were obtained with the Active Olivine; while these values do not have any physical meaning, they contribute to the statistical significance of the trends observed.

In Figure 10, the yield of UCS (in units of mol C/kg daf fuel) decreased with increasing temperature for both bed materials, and the influence of temperature was more pronounced (5fold) in the case of silica sand. The UCS values were generally lower for olivine than for silica sand. With the Active Olivine, the SPA-measurable fraction (in units of mol C/kg daf fuel) remained relatively stable at all the temperatures investigated. This is in contrast to the steep increase in the SPA-measurable tar with increasing temperature when silica sand was applied as the bed material, which reflects the conversion of UCS into aromatic tar [49].

Regarding the levels of light hydrocarbons shown in Figures 11-14b, an increase in the temperature resulted in increased yields of $\mathrm{CH}_{4}$ and $\mathrm{C}_{2} \mathrm{H}_{4}$; while the yields of the $\mathrm{C}_{2} \mathrm{H}_{6}$ and $\mathrm{C}_{3}$ species decreased in all the cases investigated, as also shown in previous publications for tests under non-catalytic conditions [43, 44, 47]. $\mathrm{C}_{2} \mathrm{H}_{2}$ is the only light hydrocarbon that changed trend depending on the activity of the bed material applied, i.e., a transition from a positive to 
a negative slope occurred for the temperature dependency of the $\mathrm{C}_{2} \mathrm{H}_{2}$ yield as the catalytic activity of the bed increased. This further supports the notion of a high activity of olivine towards $\mathrm{C}_{2} \mathrm{H}_{2}$.

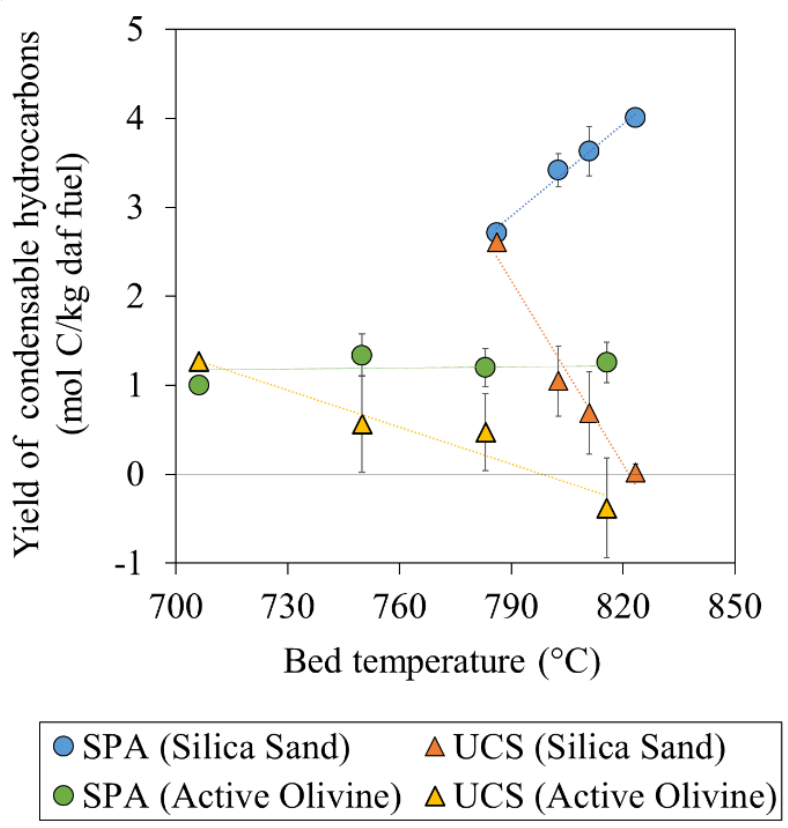

Figure 10. Yields of aromatic (SPA) and non-aromatic (UCS) condensable hydrocarbons as a function of bed temperature, with wood pellets used as the fuel in the Chalmers gasifier, an S/F ratio of 0.8 , and different catalytic activities of the bed. The sand cases are adopted from a previous study [49]. UCS, Unidentified Condensable Species with molecular weights lower than that of benzene; SPA, aromatic tar as measured by the Solid Phase Adsorption (SPA) method. Trend lines are included as a visual aid. The error bars refer to the standard deviation of the average of 3-5 repeats, when repeat measurements were acquired.

The tar fraction became enriched for benzene and naphthalene at higher temperatures, while phenolic species were more abundant at lower temperatures, as reported in previous investigations [10, 39, 48] and according to the tar maturation scheme [39]. The effect of temperature on the yield of phenols was more pronounced for the Active Olivine than for the silica sand, in agreement with the higher activity of olivine towards phenolic species reported previously $[1,5]$. 


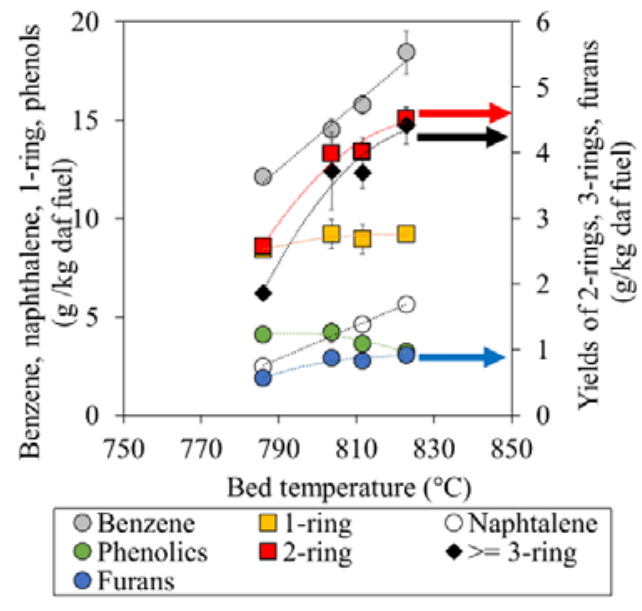

a)

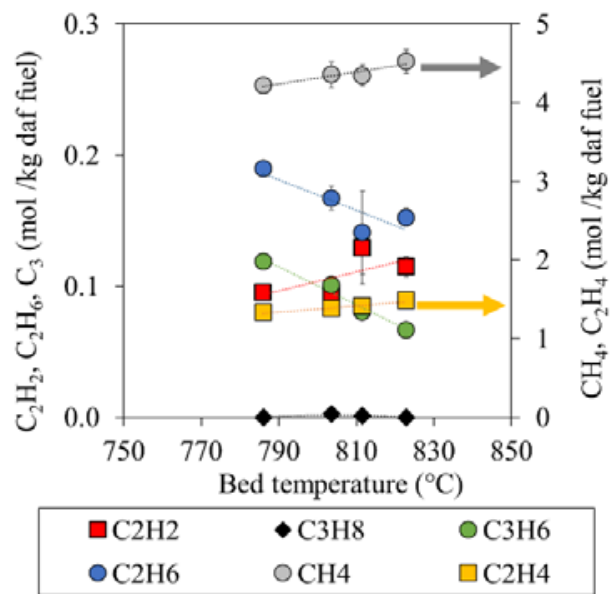

b)

Figure 11. Influence of bed temperature on the yields of: a) aromatic tar by groups; and b) light hydrocarbons. Silica sand was used as the bed material in the 2-MWth Chalmers gasifier, with wood pellets and an S/F ratio of 0.8. Shown are the average values for repeat experiments from different experimental campaigns, when available, and the standard deviation.

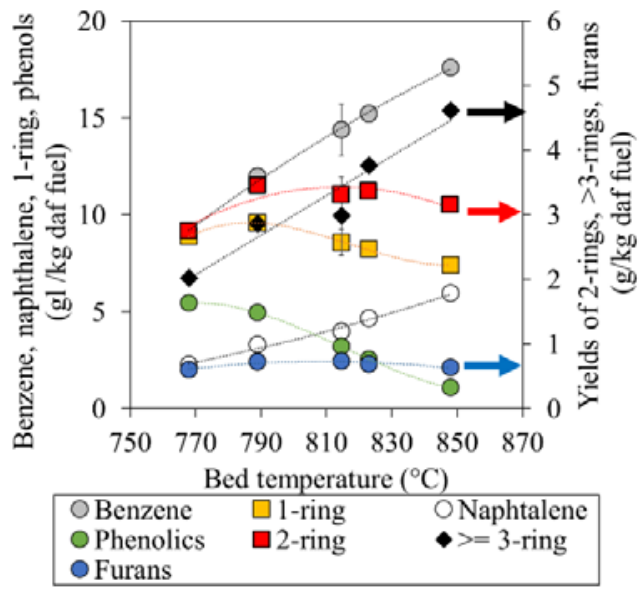

a)

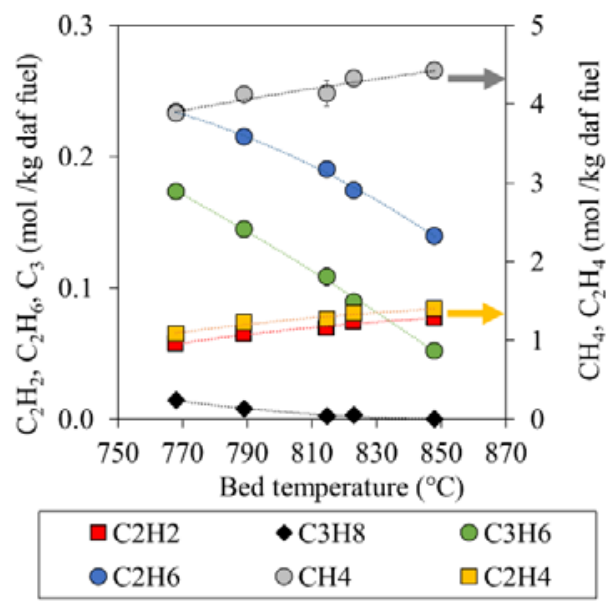

b)

Figure 12. Influence of bed temperature on the yields of: a) aromatic tar by groups; and b) light hydrocarbons. A Low-Activity olivine bed was used in the 2-MWth Chalmers gasifier, with wood pellets and an S/F ratio of 0.8. Shown are the average values for repeat experiments from different experimental campaigns, when available, and the standard deviation. 


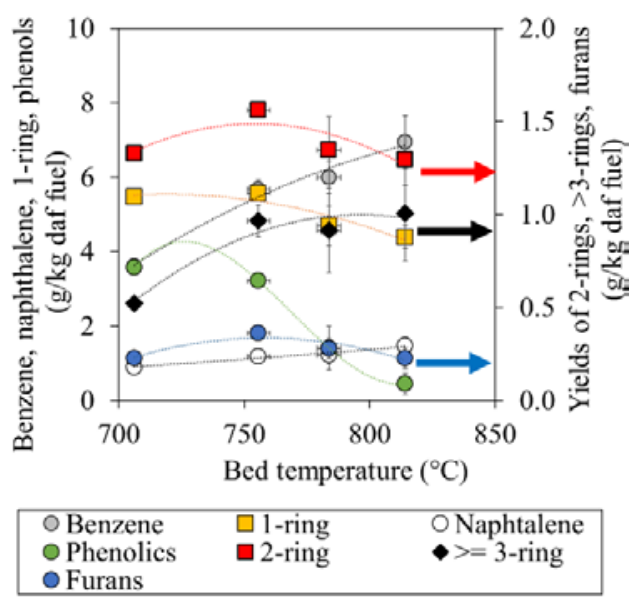

a)

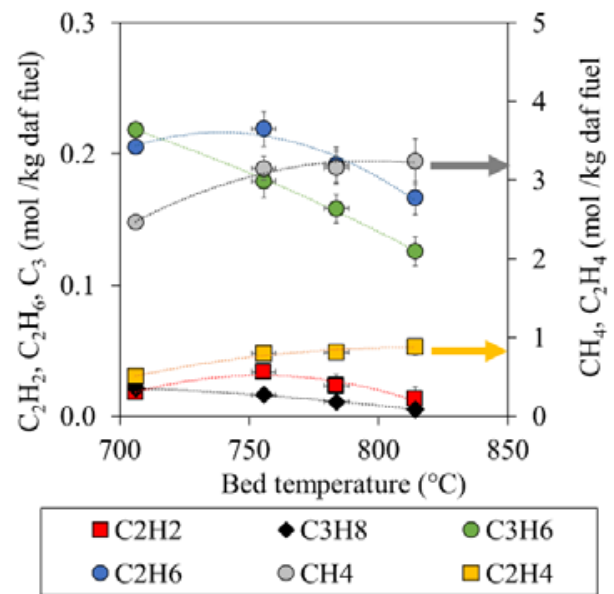

b)

Figure 13. Influence of bed temperature on the yields of: a) aromatic tar by groups; and b) light hydrocarbons. An Active olivine (no additives) bed was used in the 2-MWth Chalmers gasifier, with wood pellets and an S/F ratio of 0.8. Shown are the average values for repeat experiments from different experimental campaigns, when available, and the standard deviation.

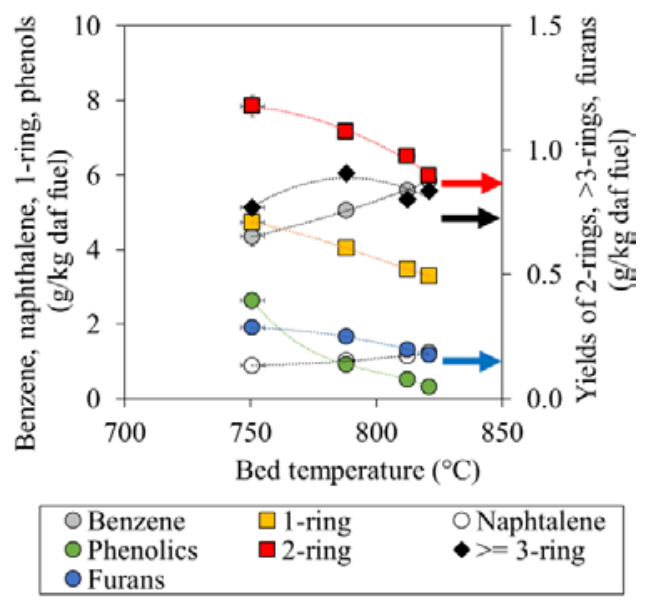

a)

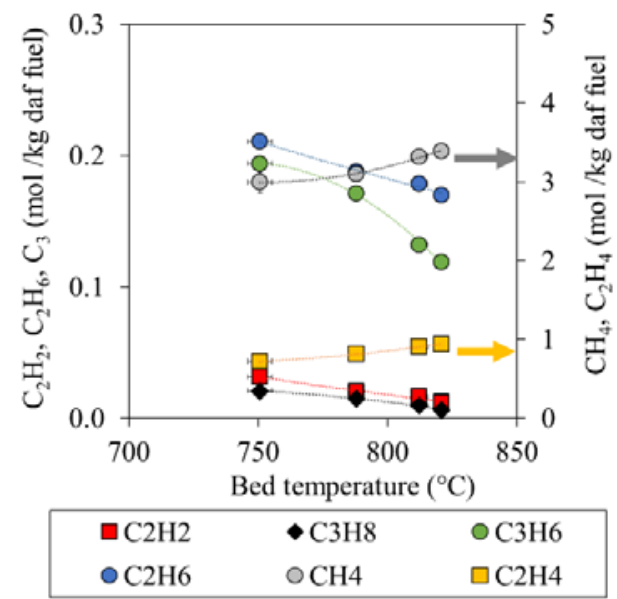

b)

Figure 14. Influence of bed temperature on the yields of: a) aromatic tar by groups; and b) light hydrocarbons. An Active olivine (ash-enriched) bed was used in the 2-MWth Chalmers gasifier, with wood pellets and an S/F ratio of 0.8. The figure shows two repeat series carried out on two consecutive days of experiments.

The yields of 1-ring, 2-ring and 3-ring groups (Figs. 11-14) show in most cases bell-shaped trends, and the maximum values move to a lower temperature as the catalytic activity of the bed increases. For instance, the 2-ring group (excluding naphthalene) exhibits a maximum yield at temperatures above $830^{\circ} \mathrm{C}$ for silica sand, at $790^{\circ} \mathrm{C}$ for the Low-Activity Olivine, and at $750^{\circ} \mathrm{C}$ for the Active Olivine. At temperatures $<820^{\circ} \mathrm{C}$, high catalytic activity is required to 
avoid aromatic growth ( $\geq$ 3-rings) with increasing thermal severity. The tendency is for aromatic growth to decrease with higher catalytic activity, as shown in Figure 15.

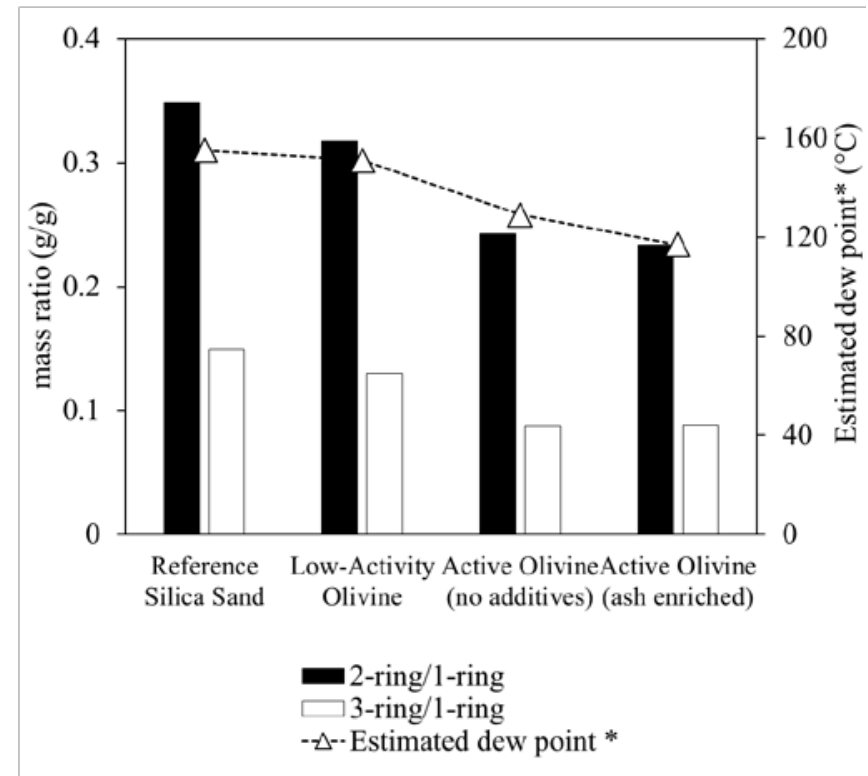

Figure 15. Mass ratios of aromatic species: 2-ring/1-ring; and 3-ring/2-ring. Bed materials with increasing catalytic activity towards tar are ordered from left to right in the figure. Steam gasification of biomass was carried out at $810^{\circ}-815^{\circ} \mathrm{C}$. Benzene and naphthalene are included in the 1-ring and 2-ring groups, respectively.* Estimated dew point of the raw gas according to the complete model by CECN-Biomass (available at http://www.thersites.nl/completemodel.aspx).

Stoichiometric analysis of the trends with increasing temperature. The contribution of the converted UCS to the formation of SPA-measurable tar and light HCs following an increase of temperature is analyzed by the derivative over temperature of the carbon-containing groups of species. The results are summarized in Figure 16 for each experimental series. It is worth noting that this analysis elucidates the interrelation between net changes in the yields of species among cases at different temperatures, whereas it does not provide information about the total yields produced.

The results show that the UCS is a net source of light HCs in all the cases investigated. In fact, the dealkylation of aromatics is insufficient, by four orders of magnitude, to explain the 
generation of light hydrocarbons caused by an increase in temperature (not shown in the figure). Higher production of light HCs is observed for the silica sand case compared to the cases with olivine.

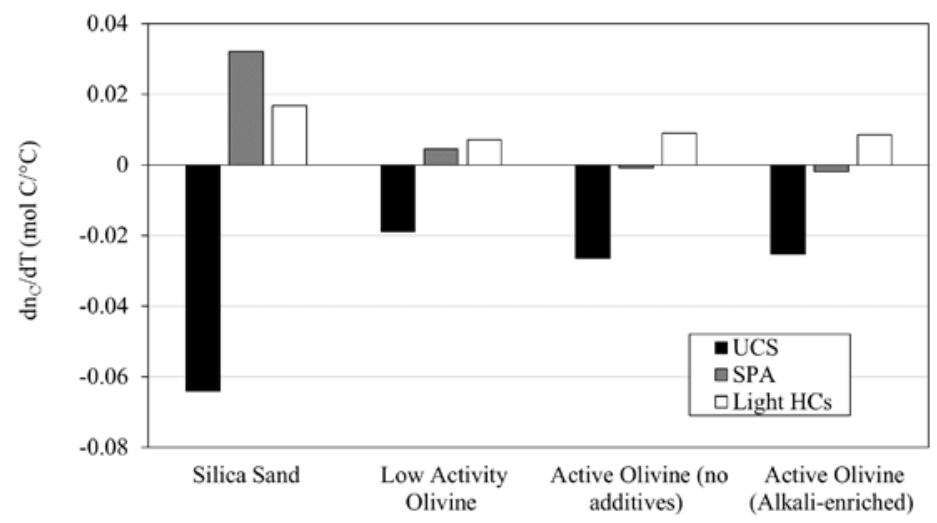

Figure 16. Net changes in molar yields of carbon with an increase in temperature by hydrocarbon groups. Temperature range $750^{\circ}-850^{\circ} \mathrm{C}$, silica sand and olivine with different levels of activity as bed materials, respectively. SPA, aromatic species measured by the SPA-method; Light $\mathrm{HCs}, \mathrm{CH}_{4}$ and $\mathrm{C}_{2-3}$; UCS, unidentified condensable species lighter than benzene.

As shown in Figure 16, with a change of temperature, the net conversion of UCS into SPAmeasurable tar shown for silica sand by Israelsson et al [49] is less pronounced for the olivine cases: $50 \%$ of the UCS is converted to SPA-measurable tar with the silica sand, $20 \%$ with the Low-Activity Olivine, while a net conversion of SPA-measurable tar is observed with the Active Olivine. The 1-ring species show the highest increase, in line with the findings of Fuentes Cano et al. [44]. There is also net production of 2-ring and heavier PAHs, which is one order of magnitude lower than that of the monoaromatic species. The net changes in the levels of monoaromatics and PAHs that occur concomitant with an increase in temperature are summarized in Figure 17 and Figure 18, respectively. 


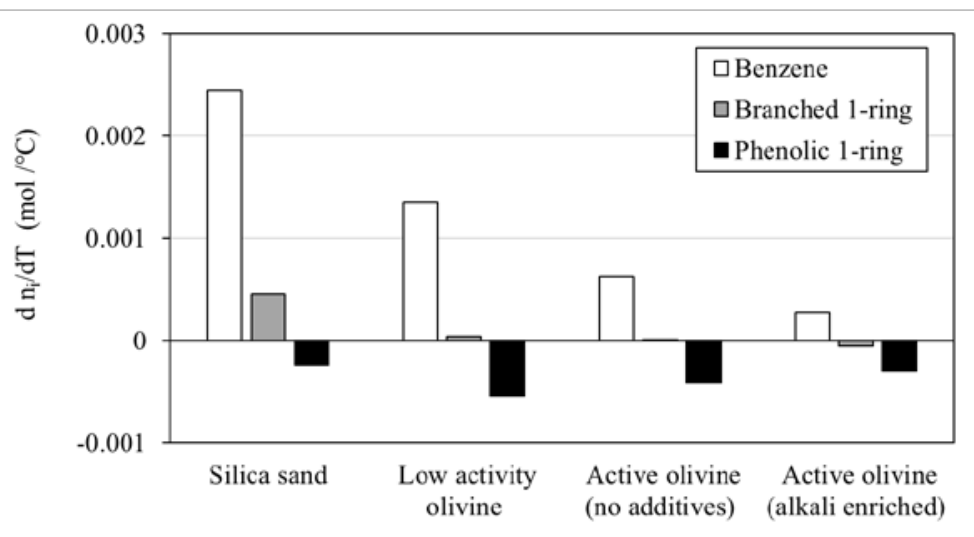

Figure 17. Changes in the molar yields of benzene, phenolic and branched 1-ring compounds for temperatures in the range of $750^{\circ}-$ $830^{\circ} \mathrm{C}$ and bed materials with increasing catalytic activity (from left to right in the figure). A positive slope indicates net production, while a negative slope indicates net conversion.

Figure 17 shows the expected $[44,45]$ mismatch between the production of benzene and the conversion of phenols/branched 1-ring species when the catalytic activity of the bed material is low. In contrast, with the use of Active Olivine, the conversion of phenols roughly corresponds to the production of benzene, which is in line with the stoichiometry of the dehydroxylation of phenol [38]. The conversion of the 2-ring group (naphthalene excluded) with the Active Olivine could justify the production of naphthalene and heavier PAHs at increasing thermal severities (Figure 18). Overall, the results show that as the catalytic activity of the bed increases, the lower is the need for an additional source of aromatic compounds (in this case, UCS) to explain the conversion of the aromatic tar species. 


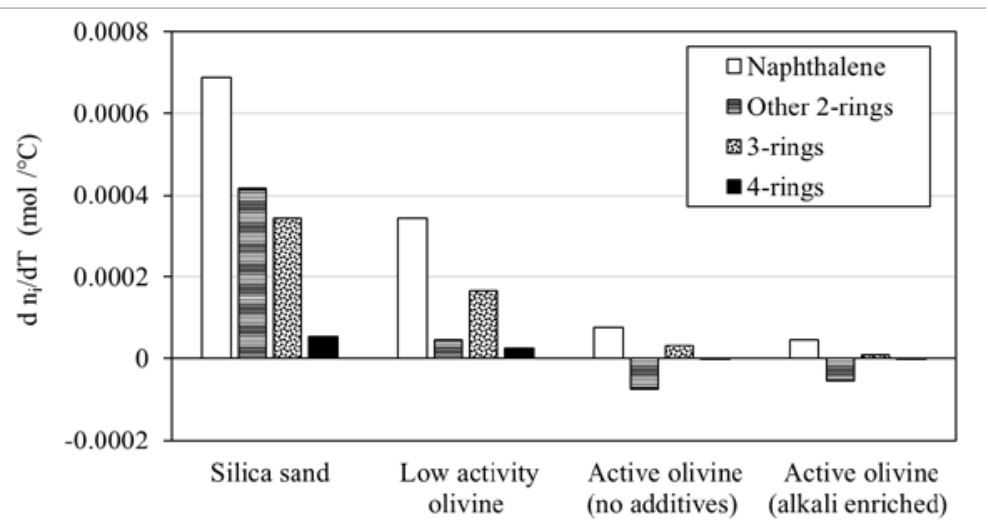

Figure 18. Changes in the molar yields of naphthalene, other 2-ring, 3-ring and 4-ring species with increasing temperature in the range of $750^{\circ}-850^{\circ} \mathrm{C}$ for bed materials with increasing catalytic activity (from left to right in the figure). A positive slope indicates net production, while a negative slope indicates net conversion.

\section{Discussion}

The lower yields of UCS obtained with the Active Olivine, as compared to the silica sand case, proves that the ash-coated olivine is catalytically active for the decomposition of early tar precursors, which are here quantified and aggregated as the UCS (Equation 2). The results indicate that the higher the catalytic activity of the bed material, the more favored is the competing conversion route for the UCS (route 1 in Figure 19). The steam reforming of early tar precursors is in line with the overall decrease in the levels of all tar species that occurs when the catalytic activity increases (as shown in Figure 9), and it is also in agreement with the hypothesis of Corella et al. [33] that in-bed catalysis prevents the maturation of nascent tars. According to the results in Figure 10, an approximately 80\% reduction in the levels of UCS and a $60 \%$ reduction in SPA-measurable tars are achieved with the Active Olivine, as compared to the use of silica sand at $780^{\circ} \mathrm{C}$. Assuming that the UCS are steam-reformed by the ash-coated olivine, roughly 40 percentage points of the reduction of SPA-measurable tar can be attributed to the prevention of tar formation through steam reforming of the UCS. The remaining $20 \%$ reduction in SPA-measurable tar can be attributed to the catalytic steam reforming of aromatic 
compounds, as demonstrated by Kuba et al. [11, 27] and in line with routes 2 and 3 in Figure 19.

Given that the details of the composition of the UCS fraction are not known, it is difficult to know whether the conversion of UCS into SPA-measurable tar occurs via intermediate species. Nonetheless, the UCS fraction, as calculated in this work, is probably rich in compounds with molecular weights lower than that of benzene, and yet they are involved in the formation of 1ring aromatics, and to some extent in the direct formation of larger PAHs. Thus, it is reasonable to propose that the observed net conversion of UCS into aromatics (monoaromatics and polyaromatics) involves some intermediate formation of light hydrocarbons, which can follow cyclization and conversion reactions into aromatic species, in line with the mechanisms proposed elsewhere [14, 36, 52]. It is suspected that the additional route to benzene formation that is required to explain the results for Silica Sand and Low-Activity olivine (in Figure 17) involves the recombination of light hydrocarbons derived from the decomposition of the UCS fraction. This route is shown with dashed arrows in Figure 19 and it is here thought to be predominant with bed materials of low catalytic activity. The formation of $\mathrm{C}_{1}-\mathrm{C}_{3}$ hydrocarbons from the UCS fraction is supported by the results presented in this work (cf. Figure 16). 


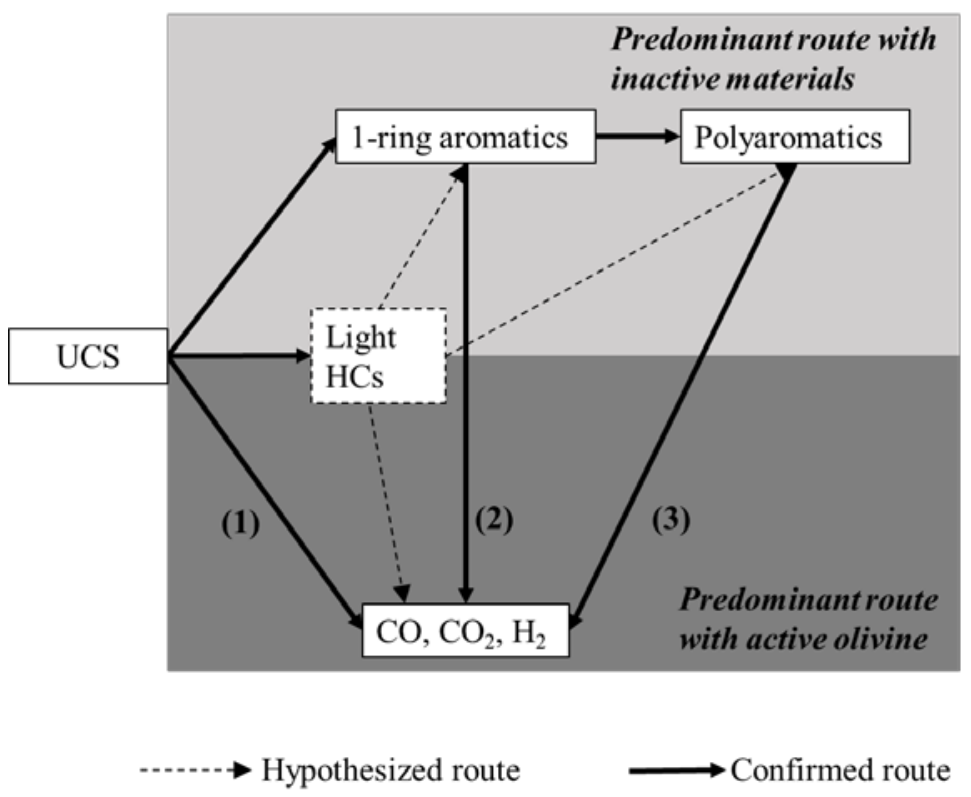

Figure 19. Summary of conversion routes identified and suggested for the UCS fraction with in-bed catalyst and under the conditions tested (steam gasification of wood pellets in the temperature range $750-850^{\circ} \mathrm{C}$ ). Route 1 has been confirmed in this work. Dashed lines indicates the hypothesized role of the light HCs in the formation of aromatic compounds in the gasifier. Light and dark gray areas indicate the conversion pathways that are predominant in the gasifier in the presence of bed materials with low and high catalytic activity, respectively.

In contrast, in the cases with Active olivine, additional sources of benzene other than phenol were not required to explain the changes in the SPA results. Recall that in the presence of the Active Olivine, the conversion of phenol with an increase of temperature roughly corresponds to the formation of benzene ( $c f$. Figure 17). Similarly, at high levels of catalytic activity, the conversion of branched 2-ring species can justify the formation of naphthalene and other PAHs. This is interpreted as an indication that the ash-coated olivine can inhibit the direct formation of aromatics from the UCS or the recombination of intermediate light HCs.

The ability of ash-coated olivine to prevent the recombination of light hydrocarbons has not been discussed previously in the literature, and the underlying mechanisms cannot be deduced from this investigation, as only net changes of the species are observed. Nevertheless, the results show distinct behaviors of $\mathrm{C}_{2} \mathrm{H}_{2}$ and $\mathrm{C}_{3}$ species as the catalytic activity increases ( $c f$. 
Figure 9) and it is, therefore, plausible that the catalytic activity of olivine can interfere with the cyclization routes involving these species [14-16, 52]. Assuming that $\mathrm{C}_{2} \mathrm{H}_{2}$ and $\mathrm{C}_{3}$ compounds are active in the formation of aromatic rings [14, 36, 52] in the experiments, it is proposed that Active Olivine prevents the cyclization routes via $\mathrm{C}_{2} \mathrm{H}_{2}$ (HACA mechanism) by decreasing the availability of $\mathrm{C}_{2} \mathrm{H}_{2}$, whereas it can passivate the $\mathrm{C}_{3}$ radicals.

Finally, it is worth noting that use of the Active Olivine resulted in $80 \%-100 \%$ conversion of UCS species with temperatures at which the UCS predominate in a silica sand bed (e.g., below $800^{\circ} \mathrm{C}$ in Figure 10). Based on a previous investigation, the fraction of volatiles in contact with the bed is estimated to be $50 \%-60 \%$ [53], which limits the contribution of heterogeneous catalysis to the conversion of UCS. This means that the thermal decomposition cannot explain the high (roughly complete) conversion of UCS under these conditions. Therefore, the highlevel conversion of UCS species is interpreted as evidence of homogeneous catalytic interactions of the ash layer with the tar precursors, in line with the findings for cellulosederived vapors reported by Jing et al. [17]. Additional contributions of homogeneous interactions of $\mathrm{H}_{2}$ and/or alkali to the prevention of polymerization [12, 13, 18, 19] cannot be discounted, as there are indications of the passivation of $\mathrm{C}_{3}$ radicals and the prevention of cyclization reactions. However, the results presented here are not sufficient to confirm the homogeneous interactions of the already formed aromatic compounds. Therefore, it can only be concluded that gas-phase interactions between nascent volatiles and bed materials contribute to the tar reduction observed in biomass gasifiers that are operating with (ash-coated) in-bed catalysts.

\section{Conclusions}

The in-bed catalysis of biomass-derived hydrocarbons by ash-coated olivine is investigated in this work. The changes in gas and tar composition induced by the activated olivine bed, and 
those induced by the various reactor temperatures $\left(700^{\circ}-850^{\circ} \mathrm{C}\right)$ are explored. The results are interpreted with the focus on the gas-phase tar chemistry and the interplay of heterogeneous and homogeneous catalytic effects. The main conclusions are that:

- the reduction of aromatic tar observed with in-bed catalysis by ash-coated olivine is a combination of: (i) catalytic conversion of aromatic species; and (ii) prevention of the formation of aromatic species;

- ash-coated olivine promotes the steam reforming of early tar precursors, which prevents their maturation into aromatic species;

- there are indications that olivine can prevent the formation of aromatics from $\mathrm{C}_{2} \mathrm{H}_{2}$ and $\mathrm{C}_{3}$ hydrocarbons; and

- there is evidence for a homogeneous catalytic effect of the ash-layer olivine towards the conversion of nascent tar.

\section{Acknowledgments}

This work was financially supported by the Swedish Gasification Center (SFC) in collaboration with Akademiska Hus, Metso AB, E.On AB, Göteborg Energi, the Swedish Energy Agency, and the BioProGReSs project. BioProGReSs has received funding from the European Union's $7^{\text {th }}$ Framework Programme for Research and Technological Development [grant number 321477]. The authors thank research engineers Johannes Öhlins, Rustan Hvitt, and Jessica Bohwalli for technical support during the experimental campaign, as well as Jelena Maric and Sébastien Pissot for execution of parts of the experiments presented.

\section{References}

1. Kirnbauer, F., et al., The positive effects of bed material coating on tar reduction in a dual fluidized bed gasifier. Fuel, 2012. 95: p. 553-562.

2. Kuba, M., et al., Influence of controlled handling of solid inorganic materials and design changes on the product gas quality in dual fluid bed gasification of woody biomass. Applied Energy, 2018. 210(Supplement C): p. 230-240. 
3. Wilk, V. and H. Hofbauer, Analysis of optimization potential in commercial biomass gasification plants using process simulation. Fuel Processing Technology, 2016. 141(Part 1): p. 138-147.

4. Thunman, H., et al., Advanced biofuel production via gasification - lessons learned from 200 man-years of research activity with Chalmers' research gasifier and the GoBiGas demonstration plant. Energy Science \& Engineering, 2018. 6(1): p. 6-34.

5. Marinkovic, J., et al., Characteristics of olivine as a bed material in an indirect biomass gasifier. Chemical Engineering Journal, 2015. 279: p. 555-566.

6. Kirnbauer, F. and H. Hofbauer, The mechanism of bed material coating in dual fluidized bed biomass steam gasification plants and its impact on plant optimization. Powder Technology, 2013. 245: p. 94-104.

7. Knutsson, P., et al., Role of potassium in the enhancement of the catalytic activity of calcium oxide towards tar reduction. Applied Catalysis B: Environmental, 2018. 229: p. 88-95.

8. Berdugo Vilches, T., et al., Comparing Active Bed Materials in a Dual Fluidized Bed Biomass Gasifier: Olivine, Bauxite, Quartz-Sand, and IImenite. Energy \& Fuels, 2016. 30(6): p. 48484857.

9. Larsson, A., M. Hedenskog, and $\mathrm{H}$. Thunman, Monitoring the bed material activation in the GoBiGas-Gasifier, in Nordic Flame Days 2015. 2015: Copenhagen.

10. Kirnbauer, F., V. Wilk, and H. Hofbauer, Performance improvement of dual fluidized bed gasifiers by temperature reduction: The behavior of tar species in the product gas. Fuel, 2013. 108(Supplement C): p. 534-542.

11. Kuba, M., F. Kirnbauer, and H. Hofbauer, Influence of coated olivine on the conversion of intermediate products from decomposition of biomass tars during gasification. Biomass Conversion and Biorefinery, 2017. 7(1): p. 11-21.

12. Umeki, K., et al., Reduction of Tar and Soot Formation from Entrained-Flow Gasification of Woody Biomass by Alkali Impregnation. Energy \& Fuels, 2017. 31(5): p. 5104-5110.

13. Hayashi, J.-I., et al., Roles of inherent metallic species in secondary reactions of tar and char during rapid pyrolysis of brown coals in a drop-tube reactor. Fuel, 2002. 81(15): p. 19771987.

14. Frenklach, M. and H. Wang, Detailed Mechanism and Modeling of Soot Particle Formation, in Soot Formation in Combustion: Mechanisms and Models, H. Bockhorn, Editor. 1994, Springer Berlin Heidelberg: Berlin, Heidelberg. p. 165-192.

15. Sharma, R.K. and M.R. Hajaligol, Effect of pyrolysis conditions on the formation of polycyclic aromatic hydrocarbons (PAHs) from polyphenolic compounds. Journal of Analytical and Applied Pyrolysis, 2003. 66(1): p. 123-144.

16. Devi, L., K.J. Ptasinski, and F.J.J.G. Janssen, Decomposition of Naphthalene as a Biomass Tar over Pretreated Olivine: Effect of Gas Composition, Kinetic Approach, and Reaction Scheme. Industrial \& Engineering Chemistry Research, 2005. 44(24): p. 9096-9104.

17. Jiang, L., et al., Catalytic behaviors of alkali metal salt involved in homogeneous volatile and heterogeneous char reforming in steam gasification of cellulose. Energy Conversion and Management, 2018. 158: p. 147-155.

18. Norinaga, K., et al., Numerical simulation of thermal conversion of aromatic hydrocarbons in the presence of hydrogen and steam using a detailed chemical kinetic model. Chemical Engineering Journal, 2011. 178: p. 282-290.

19. Hindiyarti, L., et al., Influence of potassium chloride on moist $\mathrm{CO}$ oxidation under reducing conditions: Experimental and kinetic modeling study. Fuel, 2006. 85(7): p. 978-988.

20. Cotton, D.H., N.J. Friswell, and D.R. Jenkins, The suppression of soot emission from flames by metal additives. Combustion and Flame, 1971. 17(1): p. 87-98.

21. Nowakowski, D.J. and J.M. Jones, Uncatalysed and potassium-catalysed pyrolysis of the cellwall constituents of biomass and their model compounds. Journal of Analytical and Applied Pyrolysis, 2008. 83(1): p. 12-25. 
22. Leng, E., et al., Effect of $\mathrm{KCl}$ and $\mathrm{CaCl} 2$ loading on the formation of reaction intermediates during cellulose fast pyrolysis. Proceedings of the Combustion Institute, 2017. 36(2): p. 22632270.

23. Huyghe, J., The role of alkali and earth alkaline metals as intrinsic catalysts in the fast pyrolysis of biomass constituents, in Faculty of Bioscience Engineering. 2014, University of Gent.

24. Giudicianni, P., et al., Effect of alkali metal ions presence on the products of xylan steam assisted slow pyrolysis. Fuel, 2018. 216: p. 36-43.

25. Patwardhan, P.R., R.C. Brown, and B.H. Shanks, Product Distribution from the Fast Pyrolysis of Hemicellulose. ChemSusChem, 2011. 4(5): p. 636-643.

26. Jakab, E., O. Faix, and F. Till, Thermal decomposition of milled wood lignins studied by thermogravimetry/mass spectrometry. Journal of Analytical and Applied Pyrolysis, 1997. 4041: p. 171-186.

27. Kuba, M., et al., Influence of bed material coatings on the water-gas-shift reaction and steam reforming of toluene as tar model compound of biomass gasification. Biomass and Bioenergy, 2016. 89: p. 40-49.

28. Berdugo Vilches, T., et al., Bed material as a catalyst for char gasification: The case of ashcoated olivine activated by $K$ and $S$ addition. Fuel, 2018. 224: p. 85-93.

29. Park, S.-H., K.-M. Lee, and C.-H. Hwang, Effects of hydrogen addition on soot formation and oxidation in laminar premixed $\mathrm{C2H}$ /air flames. International Journal of Hydrogen Energy, 2011. 36(15): p. 9304-9311.

30. Mze Ahmed, A., et al., Experimental and numerical study on rich methane/hydrogen/air laminar premixed flames at atmospheric pressure: Effect of hydrogen addition to fuel on soot gaseous precursors. International Journal of Hydrogen Energy, 2016. 41(16): p. 6929-6942.

31. Nelson, P.F. and K.J. Hüttinger, The effect of hydrogen pressure and aromatic structure on methane yields from the hydropyrolysis of aromatics. Fuel, 1986. 65(3): p. 354-361.

32. Jess, A., Mechanisms and kinetics of thermal reactions of aromatic hydrocarbons from pyrolysis of solid fuels. Fuel, 1996. 75(12): p. 1441-1448.

33. Corella, J., et al., Biomass Gasification in Fluidized Bed: Where To Locate the Dolomite To Improve Gasification? Energy \& Fuels, 1999. 13(6): p. 1122-1127.

34. Patwardhan, P.R., R.C. Brown, and B.H. Shanks, Understanding the Fast Pyrolysis of Lignin. ChemSusChem, 2011. 4(11): p. 1629-1636.

35. Lovell, A.B., K. Brezinsky, and I. Glassman, The gas phase pyrolysis of phenol. International Journal of Chemical Kinetics, 1989. 21(7): p. 547-560.

36. Norinaga, K., et al., Detailed chemical kinetic modelling of vapour-phase cracking of multicomponent molecular mixtures derived from the fast pyrolysis of cellulose. Fuel, 2013. 103: p. 141-150.

37. Patwardhan, P.R., et al., Influence of inorganic salts on the primary pyrolysis products of cellulose. Bioresource Technology, 2010. 101(12): p. 4646-4655.

38. Nitsch, X., et al., Conversion of Phenol-Based Tars over Olivine and Sand in a Biomass Gasification Atmosphere. Energy \& Fuels, 2013. 27(9): p. 5459-5465.

39. Milne, T.A., N. Abatzoglou, and R.J. Evans, Biomass gasifier" tars": Their nature, formation, and conversion. Vol. 570. 1998: National Renewable Energy Laboratory Golden, CO.

40. Koppatz, S., C. Pfeifer, and H. Hofbauer, Comparison of the performance behaviour of silica sand and olivine in a dual fluidised bed reactor system for steam gasification of biomass at pilot plant scale. Chemical Engineering Journal, 2011. 175(0): p. 468-483.

41. Rapagnà, S., et al., Steam-gasification of biomass in a fluidised-bed of olivine particles. Biomass and Bioenergy, 2000. 19(3): p. 187-197.

42. Kuba, M. and H. Hofbauer, Experimental parametric study on product gas and tar composition in dual fluid bed gasification of woody biomass. Biomass and Bioenergy, 2018. 115: p. 35-44. 
43. Zhang, Y., et al., Tar destruction and coke formation during rapid pyrolysis and gasification of biomass in a drop-tube furnace. Fuel, 2010. 89(2): p. 302-309.

44. Fuentes-Cano, D., et al., The influence of volatiles to carrier gas ratio on gas and tar yields during fluidized bed pyrolysis tests. Fuel, 2018. 226: p. 81-86.

45. Israelsson, M. and H. Thunman, Gasification Reaction Pathways of Condensable Hydrocarbons. Energy \& Fuels, 2016. 30(6): p. 4951-4959.

46. Neves, D., et al., Characterization and prediction of biomass pyrolysis products. Progress in Energy and Combustion Science, 2011. 37(5): p. 611-630.

47. Fuentes-Cano, D., et al., The influence of temperature and steam on the yields of tar and light hydrocarbon compounds during devolatilization of dried sewage sludge in a fluidized bed. Fuel, 2013. 108: p. 341-350.

48. Dufour, A., et al., Evolution of Aromatic Tar Composition in Relation to Methane and Ethylene from Biomass Pyrolysis-Gasification. Energy \& Fuels, 2011. 25(9): p. 4182-4189.

49. Israelsson, M., T. Berdugo Vilches, and H. Thunman, Conversion of Condensable Hydrocarbons in a Dual Fluidized Bed Biomass Gasifier. Energy \& Fuels, 2015.

50. Israelsson, M., A. Larsson, and H. Thunman, Online Measurement of Elemental Yields, Oxygen Transport, Condensable Compounds, and Heating Values in Gasification Systems. Energy \& Fuels, 2014. 28(9): p. 5892-5901.

51. Morf, P., P. Hasler, and T. Nussbaumer, Mechanisms and kinetics of homogeneous secondary reactions of tar from continuous pyrolysis of wood chips. Fuel, 2002. 81(7): p. 843-853.

52. Cypres, R., Aromatic hydrocarbons formation during coal pyrolysis. Fuel Processing Technology, 1987. 15: p. 1-15.

53. Berdugo Vilches, T. and H. Thunman, Experimental Investigation of Volatiles-Bed Contact in a 2-4 MWth Bubbling Bed Reactor of a Dual Fluidized Bed Gasifier. Energy \& Fuels, 2015.

54. Pissot, S., Berdugo Vilches, T., Thunman, H., \& Seemann, M., Recirculation of Reactive Fines an Optimization Strategy for Existing Dual Fluidized Bed Gasification Systems., in European Biomass Conference \&Exhibition. 2017, ETA-Florence Renewable Energies Stockholm.

55. Larsson, A., et al., Evaluation of Performance of Industrial-Scale Dual Fluidized Bed Gasifiers Using the Chalmers 2-4-MWth Gasifier. Energy \& Fuels, 2013. 27(11).

56. Brage, C., et al., Use of amino phase adsorbent for biomass tar sampling and separation. Fuel, 1997. 76(2): p. 137-142.

57. Israelsson, M., M. Seemann, and H. Thunman, Assessment of the Solid-Phase Adsorption Method for Sampling Biomass-Derived Tar in Industrial Environments. Energy \& Fuels, 2013. 27(12): p. 7569-7578.

58. Berdugo Vilches, T., et al., Experience of more than $1000 \mathrm{~h}$ of operation with oxygen carriers and solid biomass at large scale. Applied Energy, 2017. 190(Supplement C): p. 1174-1183. 